\title{
INTERACTIONS AND RELATIONSHIPS BETWEEN KINDERGARTEN TEACHERS AND ENGLISH LANGUAGE LEARNERS
}

by

\author{
Brittany Sullivan
}

April, 2013

Director of Thesis: Dr. Archana V. Hegde

Major Department: Child Development and Family Relations

The presence of the English Language Learner (ELL) population is ever-increasing in our Kindergarten-Grade 12 sector. With this influx of students who may need specialized attention, it is essential for educators and teacher education programs alike to focus on preparation for serving such a population. While research depicts a lack of training, it also elicits an assumed responsibility to successfully educate these students. The aims of this study are to: 1) examine relationships between native-English speaking kindergarten teachers and ELL and Non-ELL children within their own classroom and 2) examine if native-English speaking kindergarten teachers differ in their interactions with ELL and Non-ELL children within their own classrooms. Through theoretical application of Vygotsky's Sociocultural Theory and Bronfrenbrenner's Ecological Systems theory, classrooms in Eastern North Carolina were surveyed, using a demographics survey and the Student Teacher Relationship Scale (STRS), and observed, using the Emerging Academics Snapshot, EAS, to determine the process quality of each classroom and the relationships that teachers maintain with their ELL students. Analysis found that differences in teachers' relationships with ELL and Non-ELL students did exist; however, parameters of interaction were not significantly different. The implications of this study for the field of education and suggestions for future research are also highlighted. 



\title{
INTERACTIONS AND RELATIONSHIPS BETWEEN KINDERGARTEN TEACHERS AND ENGLISH LANGUAGE LEARNERS
}

\author{
A Thesis \\ Presented to the Faculty of the Department of Child Development and Family Relations \\ East Carolina University
}

In Partial Fulfillment of the Requirements for the Degree

Master of Science

by

Brittany Sullivan

April, 2013 
(C) Brittany Sullivan, 2013 


\section{INTERACTIONS AND RELATIONSHIPS BETWEEN KINDERGARTEN TEACHERS AND ENGLISH LANGUAGE LEARNERS}

\section{by}

Brittany Sullivan

APPROVED BY

DIRECTOR OF THESIS:

Archana V. Hegde, PhD

COMMITTEE MEMBER:

Sharon Ballard, PhD

COMMITTEE MEMBER:

Anne Ticknor, $\mathrm{PhD}$

CHAIR OF THE DEPARTMENT OF CHILD DEVELOPMENT AND FAMILY RELATIONS

Sharon Ballard, $\mathrm{PhD}$, Interim

DEAN OF THE GRADUATE SCHOOL

Paul J. Gemperline, PhD 


\section{ACKNOWLEDGEMENTS}

I would like to thank my major advisor, Dr. Archana V. Hegde, and my committee members Dr. Sharon Ballard and Dr. Anne Ticknor, for providing unfaltering support, encouragement, and guidance throughout this process. I would also like to thank Juliann Stalls for her assistance in IRB preparation and ensuring inter-rater reliability in the use of the EAS measure. Finally, I would like to thank my parents, Ract and Abby Lassiter, grandparents, Ted and Reba Adams, brother, Caleb Lassiter, and boyfriend, Zack Hewett, for their unconditional love and support before, during, and after this process. 


\section{TABLE OF CONTENTS}

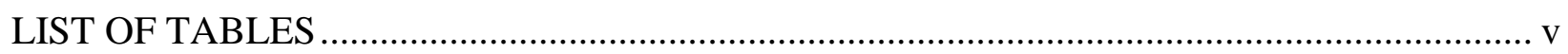

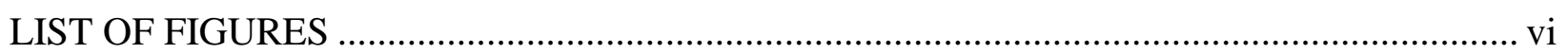

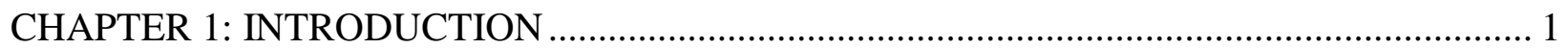

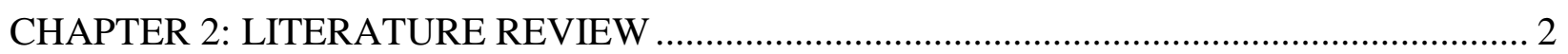

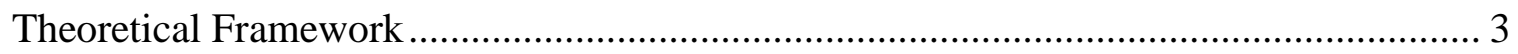

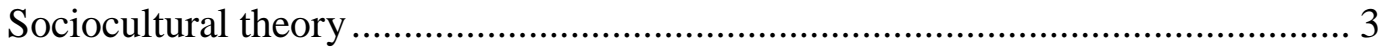

Ecological systems theory ........................................................................... 5

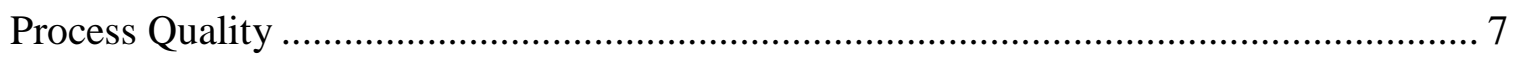

Challenges in Working with the ELL Population for Teachers........................................... 8

Programming regarding ELLinstruction............................................................. 8

Collaboration between educators ..................................................................... 13

Teachers Fostering Relationships with ELL Students .................................................... 14

Teachers Interacting with ELL Students...................................................................... 15

Ineffective interaction strategies ................................................................. 17

Effective interaction strategies...................................................................... 19

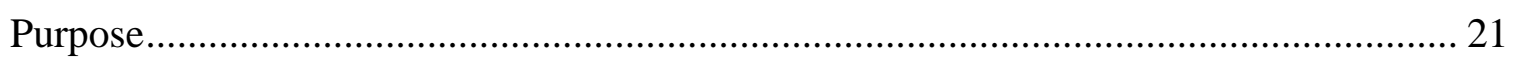

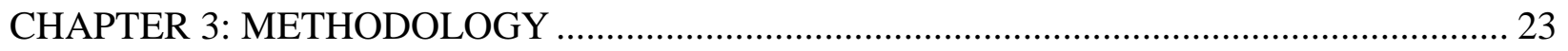

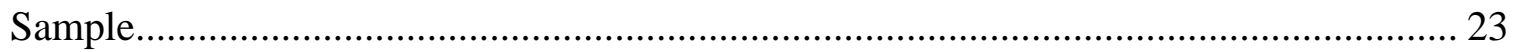

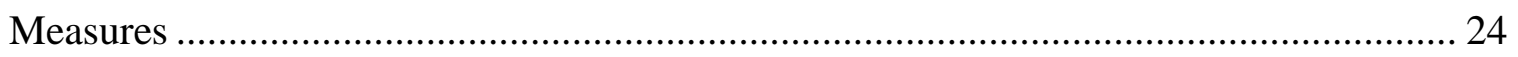

Demographics survey................................................................................ 24

Student Teacher Relationship Scale (STRS) .................................................... 25

Emerging Academics Snapshot ..................................................................... 25

Establishing Inter-Rater Reliability on Emerging Academics Snapshot ....................................... 25

Protocol Used for Data Collection ............................................................................... 26

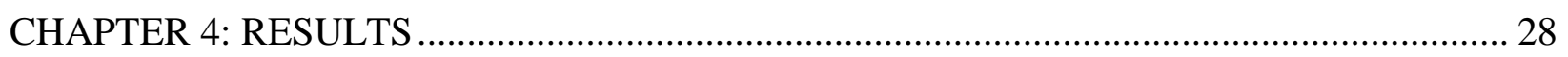

Teacher Characteristics ........................................................................................... 28

Personal teacher characteristics. .................................................................. 28

Professional teacher characteristics. .................................................................. 29

Teachers' language exposure.................................................................29 
Classroom Characteristics............................................................................................ 33

Differences in teacher relationships with ELLs and Non-ELLs...................................... 35

Differences in teacher interactions with ELLs and Non-ELLs....................................... 35

CHAPTER 5: DISCUSSION .............................................................................................. 42

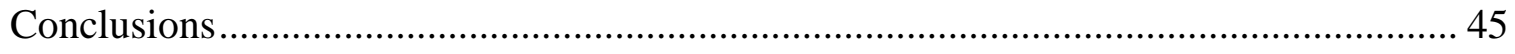

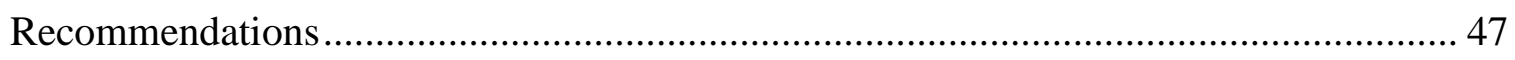

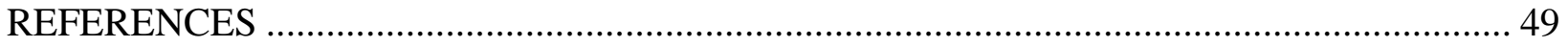

APPENDIX A: INSTITUTIONAL REVIEW BOARD (IRB) APPROVAL .............................. 56

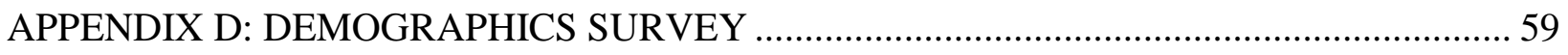

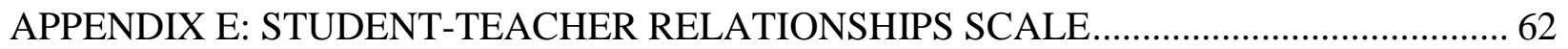

APPENDIX F: PERMISSION TO INCLUDE EMERGING ACADEMICS SNAPSHOT

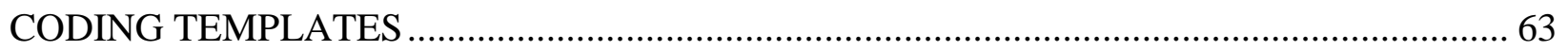

APPENDIX G: EMERGING ACADEMICS SNAPSHOT CODEBOOK ………….................... 64

APPENDIX H: EMERGENT ACADEMICS SNAPSHOT CODESHEET ……………….......... 71 


\section{LIST OF TABLES}

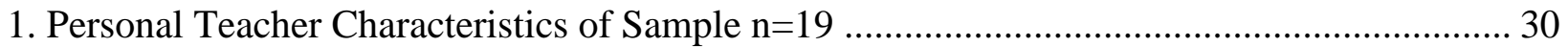

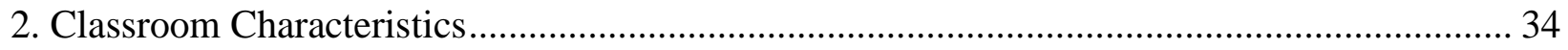

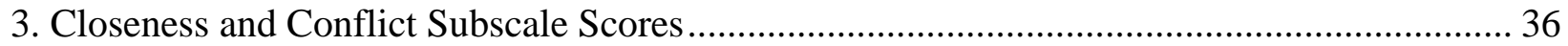

4. Interactions between Teachers and ELL and Non-ELL Student Groups ............................ 39

5. Interactions between Teachers and Male and Female ELL and Male and Female Non-ELL

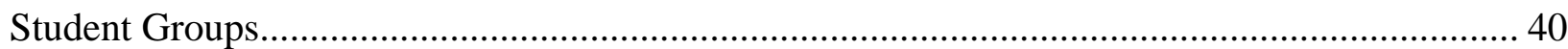




\section{LIST OF FIGURES}

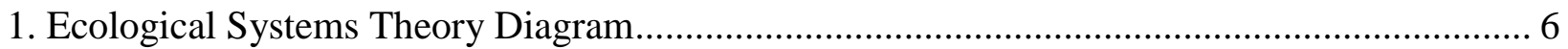

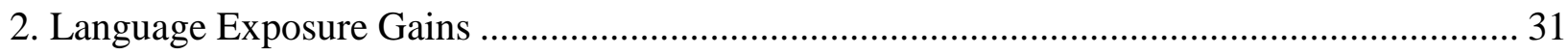

3. Interactions between Teachers and ELL and Non-ELL Student Groups ............................ 41

4. Gender Specific Interactions between Teachers and ELL and Non-ELL Student Groups...... 41 


\section{CHAPTER 1: INTRODUCTION}

English Learner (EL), English Language Learner (ELL), Limited English Proficient (LEP), and English as a Second Language (ESL) are all terms used to describe individuals who do not speak English as their first language and are taking strides to acquire the language. For the remainder of this writing, English Language Learner (ELL) will be used as the conceptual definition to describe this group. A driving force behind many changes in United States school systems is the ELL population (DelliCarpini, 2008). During the period of 1985 through 1991, the ELL student population increased by $51.3 \%$ in K-12 classrooms, to approximately 2.3 million students (Clair, 1995). In the 2003-2004 academic year, 5.5 million students were considered ELL (Batt, 2008). Although current statistics vary, children who are identified as ELL presently comprise the largest increase in the K-12 population in the United States (Han \& Bridglall, 2009); eliciting more than 50\% of public school teachers to interact with ELL students (Clair, 1995). This number is on a steady incline as some researchers project that $40 \%$ of the school age population will be ELLs by the year 2030 (DelliCarpini, 2008) and by 2050, traditional minority groups will no longer be considered minorities (Downer et al., 2012). This rapid growth of ELL presence in the school system demands attention among mainstream educators and teacher education programs alike (Batt, 2008). 


\section{CHAPTER 2: LITERATURE REVIEW}

"Educating ESL students is complex, it challenges social, political, and pedagogical assumptions, it is context specific and dilemma ridden" (Clair, 1995, p. 193). Over $41 \%$ of public school teachers are now responsible for instructing ELLs (Pawan, 2008). Yet, educators with the knowledge and skills required to work with ELL students are in limited supply (Batt, 2008); and, a resounding notion in current literature is that teachers do not feel adequately prepared to work with ELL students (Clair, 1995; Curtin, 2005a; Pawan, 2008; Teale, 2009; Vacca-Rizopoulos \& Nicoletti, 2008). In 2005, de Jong and Harper conducted a study that supported these results; however, revealed that only $12.3 \%$ of these teachers had received more than eight hours of professional development geared toward instructing ELL students. The preparation that instructors receive for teaching these classrooms leaves much to be desired in terms of training and confidence; yet, it is assumed to be adequate enough to sustain. With the proliferation of the ELL population in United States schools, these issues cannot be ignored. There is a wealth of information in current literature regarding K-12 ELL populations; however, there is a lack of information geared towards specific interactions between elementary school populations of ELLs, specifically Kindergarteners, and their teachers; the process quality within mainstream classrooms; and, the effect this has upon this populations' language development once mainstream teachers are given the responsibility of instructing them. Thus, in this particular study we specifically focus on two dimensions of process quality; interactions and relationships. The main purpose of this study is to examine kindergarten teachers' relationships and interactions between ELL and Non-ELL students. 


\section{Theoretical Framework}

A theory is a set of interconnected ideas that emerge from the process of articulating and organizing ideas to comprehend a particular event (Boss, Doherty, LaRossa, Schumm, \& Steinmetz, 1993). According to Robert Pianta (1999), the use of theory offers evidence as to the effectiveness of an attempt, as well as a guide to important decisions of how to focus strengths and resources.

Sociocultural theory. While many theories are applicable to the academic aspect of classrooms, Lev Vygotsky proposed sociocultural theory which posits that children learn through social interactions (Vygotsky, 1978; Vygotsky, 1986). Vygotsky proposed that humans utilize tools developed from their cultures, including speech and writing, to mediate their environments (Learning Theories Knowledgebase, 2012). Major elements of sociocultural theory note that children actively seek knowledge through interacting with their environment. This interaction facilitates development in a culturally modified fashion (Learning Theories Knowledgebase, 2012). As culture has an impact on language as a communication process; language, in turn, affects both cognitive and social domains of development.

The fact that ELLs are exposed to their native culture at home and a diverse culture at school impacts their ability to maintain academic learning in the English language (Hammond, 2008b).

The school must allow cultural elements that are relevant to the children to enter the classroom...thereby enabling the child to move through relevant experiences from the home toward the demands of the school as representative of a diverse society (Garcia, 1992, p. 82). 
It is important for teachers to understand that a student's first language plays an essential role in the acquisition of a second language; learning a second language is a long and difficult process and, learners acquire second languages in different ways. Relying too heavily on similarities that exist between first and second language acquisition may neglect differences between first and second language learning and the influence they have on successful oral language, literacy development and academic achievement for ELLs (de Jong \& Harper, 2005). Research demonstrates that cognitive, cultural, and social variables have bearing on knowledge acquisition, as well as second-language acquisition (August \& Garcia, 1998). Teachers must acknowledge these aspects so that they are able to provide effective assistance to all ELL students. Ernst-Slavit, Moore, and Maloney (2002) noted that language is best developed in an assortment of settings that promote talk and interaction; literacy is part of language, thus reading and writing development is fostered by speaking and listening.

Vygotsky's theory further postulates the idea of a zone of proximal development (ZPD), or the expanse between an area of which a child can master a task with the help and instruction, or scaffolding, of an instructor/parent/guardian or independently (de Jong \& Harper, 2005; Learning Theories Knowledgebase, 2012; Shabani, Khatib, \& Ebadi, 2010). Teachers can reduce the cognitive, cultural, and language loads that burden students and evaluate their teaching strategies and approaches by gauging changes in ELLs' zones of proximal development (Gibbons, 2003; Gibbons, 2008; Maxwell, 2011; Pawan, 2008). Should teachers effectively use the information provided by their students' ZPDs, students' achievements or failures should not be viewed as merely resultant of the students' innate ability or background, but also as the measure of the context of interactions between teachers and students (Gibbons, 2003). While the environment of a classroom is dependent upon a number of components, providing tailored 
support for both students and teachers is vital to help ameliorate the performance of each party within the classroom (Han \& Bridglall, 2009).

Ecological systems theory. Bronfenbrenner proposed ecological systems theory which posits that all parts of a family are interconnected and cannot be viewed separately (White \& Klein, 2008). The family is viewed as an integrated system and that the system effects and is effected by the surrounding environment (Bronfenbrenner, 2005). Similar to Bronfrenbrenner's ecological systems theory, a classroom environment can be viewed as a system that is affected by various spheres of influences. Those influences include but are not limited to, classroom characteristics such as the ratio of teachers to students, the education/experience of teachers, beliefs that the teachers hold, the number of children, and the amount and quality of the classroom space; characteristics of the school such as financial resources, management styles, types of programs, and size; regional characteristics such as local regulation, the sub-culture, and the economic well-being; and, finally the country characteristics that consist of the culture, regulation, and the economic status (Cryer, Tietze, Burchinal, Leal, \& Palacios, 1999). These levels coincide most accurately with Bronfrenbrenner's Micro, Meso, Exo, and Macro systems of ecological systems theory, respectively. These systems can be seen in Figure 1. Equally important aspects of a child's life, such as family and community also coincide with Bronfrenbrenner's ideas. Additionally, classrooms are described through both structural and dynamic features that have a significant impact on the processes that occur within each classroom and are embedded within the various spheres of influence listed previously (Cryer et al., 1999). 
Figure 1. Ecological Systems Theory Diagram

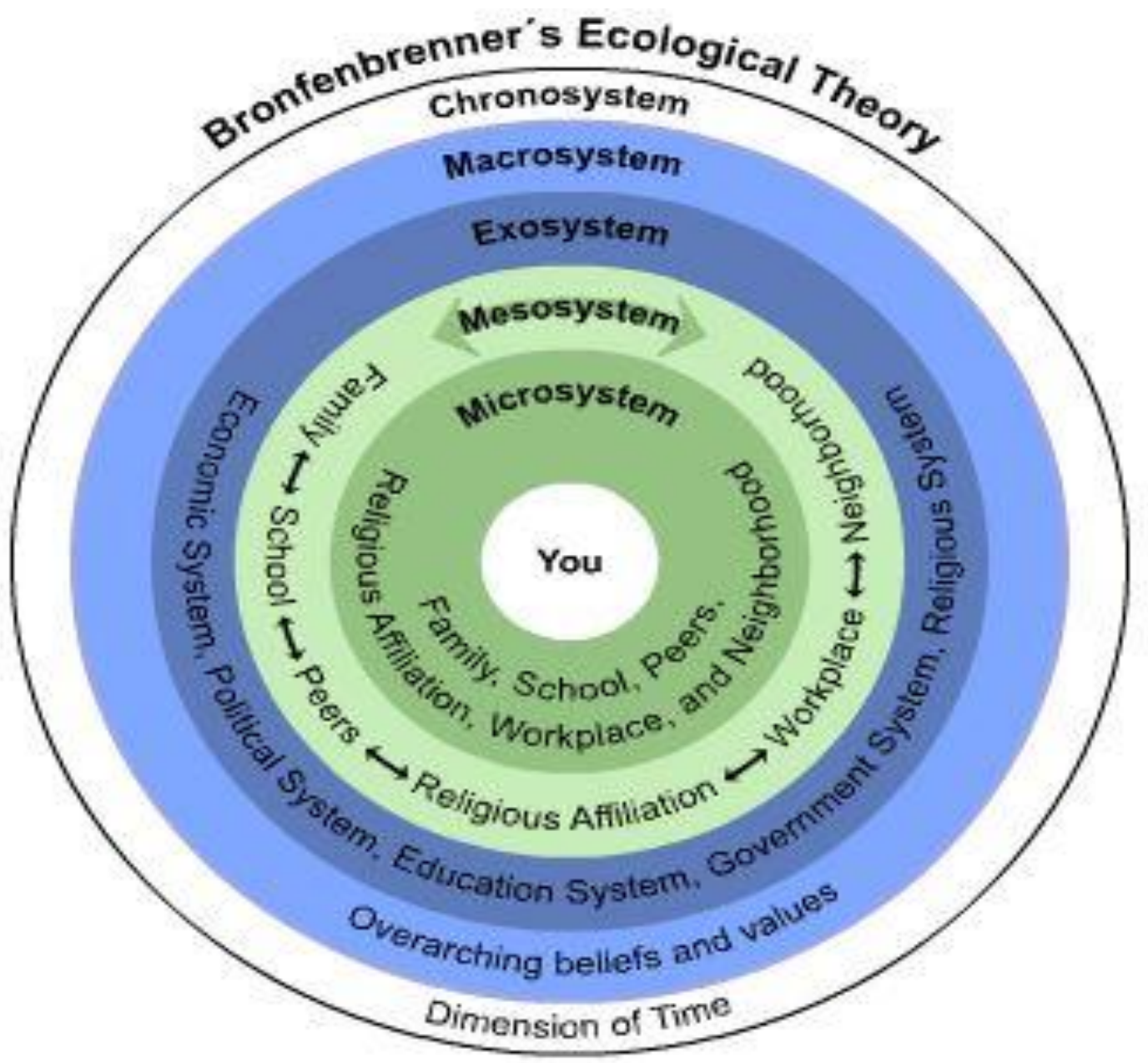




\section{Process Quality}

Process quality is representative of the experience children have in their classrooms, including but not limited to, the interactions that they have with their teachers and the activities/materials that are provided to them (Phillipsen, Burchinal, Howes, \& Cryer, 1997). Tietze, Cryer, Bairrão, Palacios, and Wetzel (1996) list the core elements of process quality as safe care, healthful care, developmentally appropriate stimulation, positive interaction with adults, encouragement of individual emotional growth, and promotion of positive relationships with other children. It is speculated that proximal aspects of classrooms will impact process quality more so than distal aspects; proximal influences are structural variables that are present in the classroom, such as teacher characteristics (Cryer et al., 1999). Mashburn et al., (2008) found that a measure of process quality that was most reliably correlated with the development of children was the extents of the interactions between the teacher and the child. As teachers are organizers, managers, providers of activities, and interact with children, their characteristics should directly influence the quality of children's experiences (Cryer et al., 1999).

Quality of classrooms across the nation is multidimensional as it takes into account a variety of classroom features. Classroom quality is defined by a set of required standards regarding structure and design allocated by each state; and, it is measured most often by the number of minimum standards with which a program complies (Mashburn et al., 2008). A number of tools have been developed to effectively measure process quality. The Early Childhood Environment Rating Scale (ECERS), the Classroom Assessment Scoring System (CLASS) and the Caregiver Interaction Scale (CIS) are just a few of the available tools. Each of these tools use observations to gather the data needed in order to correctly assess the process quality of classrooms. The Emerging Academics Snapshot (EAS) is another observation tool 
that, similar to the previous mentioned, is used to gauge children's instruction and engagement throughout academic activities; however, the EAS contributes further by also gauging teachers' engagement.

\section{Challenges in Working with the ELL Population for Teachers}

As more teachers increasingly discover themselves teaching students from diverse linguistic and cultural backgrounds, the task of assisting them in becoming successful speakers of English increases as well (Carrison \& Ernst-Slavit, 2005; de Jong \& Harper, 2005; Mesa-

Baines \& Shulman, 1994). A large majority of teachers are novices to instructing more culturally and linguistically diverse students; accompanying this experience, teachers must find appropriate and effective instructional strategies to accommodate the learning needs of this particular student population (Carrison \& Ernst-Slavit, 2005). The need for teachers to acquire the understanding and skills to help ELLs succeed academically is more urgent than ever (VaccaRizopoulos \& Nicoletti, 2008) as it has been proven that it takes a period of five to seven years for students to become proficient in a second language (Batt, 2008; Chamot, 1983; Curtin, 2005b; Miller \& Endo, 2004; Wertheimer \& Honigsfeld, 2000). As the teaching force remains predominantly white, female and monolingual, the diverse language and cultural backgrounds of students are growing drastically; meaning teachers must rise to the challenge, adjust their teaching methods, equip themselves with the knowledge and skills to accommodate these differences, build on individual strengths, and meet the needs of ELLs (Batt, 2008; DelliCarpini, 2008; Vacca-Rizopoulos \& Nicoletti, 2008).

Programming regarding ELLinstruction. Students and teachers alike no longer have the luxury of time to ameliorate the process of acclimation and language learning as components 
of the No Child Left Behind (NCLB) act of 2001(PL 107-110) now enforce that English Language Learners participate in standardized testing in English within three years of entering school systems (Batt, 2008; Curtin, 2005a; Curtin, 2005b; Han \& Bridglall, 2009). In order to accommodate this legislation, schools are moving away from extended bilingual instruction, that has been proven effective, to English only instruction (Han \& Bridglall, 2009). Educational programs are available in schools throughout the United States to assist ELLs, but a vast array of learner and contextual aspects must be taken into consideration for these programs to be effective. Ecological systems theory provides insight as to how such learner and contextual aspects can be viewed independently as well as collectively. Aspects include but are not limited to: cultural backgrounds, language practices, educational experience, variances in age and language/literacy development, as well as the status of the language used in the child's home and culture in relation to the language and culture they are assimilating (Platt, Harper \& Mendoza, 2003). While programs do exist, in order to qualify for services provided by these programs, students must score at $35 \%$ or below on language proficiency scales (equivalent to a two yearold level of everyday English); once above this level, students are no longer qualified for these services (Ernst-Slavit et al., 2002). As a result, ELLs are all too often placed in mainstream classrooms before gaining the degree of proficiency in academic language to compete on a level playing field with their native English-speaking peers (Harklau, 1994).

With ESL instruction being limited by a student's proficiency level of $35 \%$ (Ernst-Slavit et al., 2002), the differences in perceptions of students and teachers regarding ESL instruction are quite interesting. Strang, Winglee, and Stunkard (1993) conducted a survey of high school sophomores and their teachers in regards to their perceptions of the students' language proficiencies. When just the teachers' surveys were taken into account, 97,000 students were 
perceived to be qualified for ESL services. However, when students' perceptions were investigated, the number surged to 256,000, indicating that students do not feel their English is up to par; but, because these students scored above $35 \%$, they are not considered to be qualified for ESL services (Ernst-Slavit et al., 2002).

Requirements of NCLB and 35\% or below proficiency levels are disadvantageous to the process of second language acquisition. In order to generate practices that are effective for communication between teachers and ELLs, several aspects of language acquisition must first be conveyed. Cummins (1989) suggested the idea of Basic Interpersonal Communication Skills (BICS), which is social language used every day, and Cognitive Academic Language Proficiency (CALP), which is cognitive, literacy and language skills. Cummins asserts that BICS can be mastered within a two year period, but CALP can take up to twelve years. He further stresses that by developing CALP, BICS will follow, but the reverse is not true as students may exhibit fluency in the hallway; but, this does not communicate to the classroom (Black, 2005; Chamot, 1983; Curtin, 2005b; de Jong \& Harper, 2005; DelliCarpini, 2008; Ernst-Slavit et al., 2002; Wertheimer \& Honigsfeld, 2000). The span in years that it takes to develop CALP is reflective of the varying degrees of academic preparation and literacy skills that students carry with them to secondary education (Ernst-Slavit et al., 2002). Mandating ELL students to test in English within a three year period of entering the school system puts them at a great disadvantage as they have yet to fully develop CALP within that time span.

Though programs may be beneficial, areas of improvement include acknowledging students' prior knowledge and experiences that they bring with them to their current circumstance, as well as increasing the accessibility of programs as most students only spend a portion of their day in the ESL or bilingual classroom (Clair, 1995; Ernst-Slavit et al., 2002; 
Wertheimer \& Honigsfeld, 2000). The practice of time spent split between an ESL/bilingual classroom and a mainstream classroom is often referred to as "pull out" or "push in," where students that may need supplemental instruction in a certain content area are "pulled out" from the mainstream classroom and sent to the ESL/bilingual classroom or if students have adequately grasped a concept, they may be "pushed in" to a mainstream classroom from an ESL/bilingual classroom (Honigsfeld, 2009; Lueck, 2010; Wertheimer \& Honigsfeld, 2000). This is a prime example of the efforts being made within the school systems to gradually move toward English only instruction; and, this type of programming forecasts a despondent future for a myriad of elementary age students (Black, 2005). An increasing number of ELLs are entering middle and high schools with interrupted formal education (DelliCarpini, 2008). According to current statistics, $20 \%$ of high school ELLs and 12\% of middle school ELLs have missed at least two years of formal education (DelliCarpini, 2008). While the reasons behind these interruptions of instruction can only be speculated, it is of the utmost importance for teachers to make the most of the time spent with this population and provide instruction that will benefit them academically. This time is essential to their education as failure can become the incentive for middle and high school students to drop out of the educational system. (Curtin, 2005b). Sheraga (1980) indicated that high school may be ELL students' last chance or the beginning of a new chance for selfrealization. However, it is becoming increasingly difficult to bridge the existing gap between ELLs level of content area knowledge and the grade level expectations that have been set by district, state and federal policies (Wertheimer \& Honigsfeld, 2000).

Many practices, not just in regards to ELLs, in United States schools are influenced by the implementation of No Child Left Behind and leave both students and teachers without much room to negotiate academic needs. Despite discrepancies between legislation and effective 
practices, it is essential to provide all students, English speaking or not, with an environment that is conducive to learning and supportive of their academic needs. The lack of training in effective strategies for ELL instruction impacts the variance of teachers' instructional styles and their ability to facilitate interaction with non-native English speakers in their classroom (Harklau, 1994). By supplying opportunities and encouragement for teachers to discuss their experiences, teachers reported becoming more systematic, more aware of their actions in the classroom, and more aware of their students' needs (Hammond, 2008a). Children who are in the same grade and lack understanding of the English language will have a wide variety of previous experiences that must be acknowledged. In addition to developmental statuses, age upon arrival, length of residency within the United States, and grade upon entry into the public school system are variables that must be taken into consideration, as well as categorizing variables within ELLs academic performance levels (Curtin, 2005b). This population of students will also have developed their own schemas for concepts and will be either more or less inclined to acquire English as a second language. Individual learning strategies and homogeneous grouping activities can be devised once it is determined what children need to learn in concepts and the English language. When children expose their individual language learning styles and strategies, an assortment of techniques and approaches should be employed in order to capitalize on each child's preferred learning style (Chamot, 1983).

There are programs, however, that exist in order to amend the gap between teachers and ELL students. For example, TELL or Teaching English Language Learners is a grant funded program that provides 15 credits of graduate level course work to teachers who desire to learn how to work with ELLs in their classroom and demonstrate interest, commitment, and dedication to the issue of creating successful learning environments for ELLs (DelliCarpini, 2008). 
Likewise, Operation Ser (Ser is a Spanish verb that translates to "To Be" in English) is an antipoverty program that takes in at-risk ELL students and provides training for job skills and academic equivalents to a GED certificate. The students involved with this program are challenged to succeed and capable of doing just that as the mentors have substantial control over the curriculum. By having the power to determine what subject each individual needs to devote more time to, these mentors can shape their syllabus accordingly to enhance the student's ability to succeed (Adamson, 2005). In an edition of Education Week, an article focusing on the difficulty of establishing these early education programs argued that studies that had been conducted provide evidence for expansion of such programs as a correlation was found between participation and higher educational attainment (Jacobson, 2007).

Collaboration between educators. Penfield's 1987 study depicted that in lower elementary grades, mainstream teachers believed the teaching of sight word mastery and phonics should be the responsibility solely of the ESL teacher. This belief is also supported by de Jong and Harper's study conducted in 2005. A quarter of a century later, the primary responsibility for the instruction of ELLs can no longer rest on the shoulders of ESL teachers; collaboration between ESL and mainstream teachers must be followed through in order to support the academic needs of the students. While content area/grade level teachers must be able to be language teachers to ELLs; ESL teachers must also be able to facilitate and support the development of content concepts (DelliCarpini, 2008; Vacca-Rizopoulos \& Nicoletti, 2008; Wertheimer \& Honigsfeld, 2000). This element of collaboration between mainstream and ESL teachers reinforces the interaction of the mesosystem in Bronfenbrenner's Ecological Systems theory. Unfortunately, recent literature depicts a lack of interdisciplinary collaboration in schools across America (DelliCarpini, 2008; Honigsfeld, 2009; Pawan, 2008). Platt, Harper, and 
Mendoza (2003) indicated that inclusion had received a bad name in a district in which they had conducted their study due to mainstream teachers' lack of consistency in strategy implementation and collaboration.

\section{Teachers Fostering Relationships with ELL Students}

Relationships are conceptually defined as connections, associations, or involvement between individuals. According to Robert Pianta (1999), relationships between children and adults play a critical role in a child's development as they form and shape its course. These relationships that begin early in life, typically with one's parents, help to solidify the foundations of the child's development that support what is asked of a child in school: communication, cooperation, amicability, determination, motivation, and exploration. This structure is expected to be carried on throughout the school years, with continued support from parents; but, can be challenged by changes in relationships (Pianta, 1999). There is often a lack of cross cultural relationships (due to language barriers, cultural differences, and time) between teachers and their ELL students and their families; constituting a change in relationships.

A common belief across the teaching population is that teaching is the same despite the types of students in your classroom; however, this negates the importance of individual difference and negatively affects the classroom environment (Clair, 1995). Unfortunately, cultural scaffolding is seldom referenced in classrooms; and, embracing the variety of cultures and demonstrating that the presence of these cultures are valued will only add to classroom environment, not detract from it (Black, 2005; Curtin, 2005b; de Jong \& Harper, 2005; ErnstSlavit et al., 2002; Miller \& Endo, 2004; Pawan, 2008). Eugene Garcia depicts the importance of embracing diverse cultures in his 1999 work, Student Cultural Diversity: Understanding and Meeting the Challenge: "we must start with their culture....and look first to determine how they 
seek to know themselves and others and how their expertise and experience can be used as the fuel to fire their interests, knowledge and skills...for they are rich in assets” (p. 82). Current research indicates that a school's resources and learning environment are important to ELLs in particular, because teaching is fundamentally relational (Han \& Bridglall, 2009; Pawan, 2008). Cross cultural relationships must be developed between teachers and students in order to create a positive learning environment (Miller \& Endo, 2004, Pawan, 2008). However, mainstream teachers may find it difficult to create a truly welcoming environment for ELLs in their classroom as there are substantial linguistic and conceptual differences between teachers and students when the same language, assumptions, or life experiences are not common to both groups (Gibbons, 2003; Youngs \& Youngs, 2001). The extant language barrier between students and teachers creates a detriment to the process of forming healthy relationships within the classroom. It is essential for these cross cultural relationships to be forged to enhance both the individual child's development as well as the classroom environment.

\section{Teachers Interacting with ELL Students}

Interaction is conceptually defined as reciprocal action or influence. As interactions can be both positive and negative, it is important to consider the relational aspect of interaction and instruction. Previous research has found that the elementary years are the most beneficial for language instruction (Teale, 2009). At the age of five, when most children begin school, children are novices to the social environment in which they participate daily. From the age of five to adolescence, physical, cognitive, social and emotional transitions occur that ultimately have an impact on the amount, kind, content and significance of interactions between children and their environments (Collins, Madsen, \& Susman-Stillman, 2002). The socialization processes that children endure are contextual, multidirectional and transactional depending upon their 
environment. Therefore, classroom environments and teaching styles are exceedingly influential on the course of language and content instruction. Curtin, (2005a), depicted the importance of creating an interactive environment rather than a didactic one in a classroom. In her study, she found that interactive teachers appeared to be the most culturally responsive and more conscious of the instructional and academic needs of ELLs. Van Lier (1996) stated that for a person to acquire knowledge, they must be an active participant in an activity that is somewhat familiar and somewhat novel, so that they may focus on useful changes and increase attainable knowledge (Gibbons, 2003). Gibbons (2003) further noted that language learning is a socially mediated process where both students and teachers must actively participate in the coconstruction of language and curriculum knowledge. These accounts parallel Vygotsky's sociocultural theory in that he promoted students playing active roles, so that learning becomes a reciprocal experience for the student and teacher (Learning Theories Knowledgebase, 2012), as well as the components of Zone of Proximal Development and scaffolding. It is however, the teacher's responsibility to develop appropriate strategies and approaches for the targeted group if all students are to be active participants in the classroom community (Vacca-Rizopoulos \& Nicoletti, 2008). Supplementing the idea of scaffolding, observational learning plays a large role in the school environment as learning in social situations is achieved at a faster rate through observing the behavior of others (Ledford, Gast, Luscre, \& Ayres, 2008).

Two major issues that currently plague the instruction of ELL students in mainstream classrooms are that teachers desire quick fixes and illuminate that the need to understand second language acquisition is dire; but also, teachers need to make accommodations in regards to their beliefs, values, and attitudes toward ELLs in order to facilitate their academic achievement in the classrooms (Clair, 1995). Unfortunately, the attitudes that teachers exhibit toward ELLs are 
likely to affect what students learn and how students respond to the challenge of learning a second language; therefore, questions of mainstream teachers' abilities to effectively instruct these students still remain (Clair, 1995; de Jong \& Harper, 2005; Youngs \& Youngs, 2001). Sociocultural theory posits that learning is a reciprocal experience for both teachers and students (Learning Theories Knowledgebase, 2012), which supports the notion of interface between the microsystem and the individual of ecological systems theory. An example of such is the objective and public evaluation from nonfamily members that children experience in the school environment. It is essential for teachers to provide welcoming child-centered environments that are conducive to children's learning, as a major issue that pervades classrooms is that of the selffulfilling prophecy; or, an expectation that elicits certain behaviors, therefore confirming that expectation (Encyclopedia, 2012). These expectations are often born from preconceived stereotypes; for example, the silent period of ELLs which will be further explained in following paragraphs.

Ineffective interaction strategies. With mounting, and often novel, challenges, mainstream teachers are likely to represent wide variations of enthusiasm and readiness to incorporate ELL students into their classrooms (Youngs \& Youngs, 2001); and, can readily identify pros and cons associated with teaching this population. Teachers often are misinformed about the native cultures of English language learners and expect less of students using nonstandard English, which can also elicit a self-fulfilling prophecy. For example, the silent period, as described by Krashen (1992), is often misinterpreted by teachers as an unwillingness to participate; yet, this period plays a crucial role in language acquisition and cultural adaptation (Ernst-Slavit et al., 2002; Youngs \& Youngs, 2001). The silent period is characterized by active listening in order to process the language that is being heard and applying it to the context in 
which it is being used. This period of second language acquisition is similar to the pre-speech stage of first language acquisition in that infants take in what they hear and when they are ready, they replicate it. Despite misconceptions, teachers that have more positive attitudes toward the inclusion of ELLs in their classrooms have been found to have had a foreign language or multicultural education course, have had some ESL training, have lived or taught outside of the United States, have interacted with a culturally diverse population and are female. This leaves a vast number of teachers with either indifferent or negative attitudes toward ELL inclusion. As many teachers concede feeling inadequately prepared to accommodate ELLs in their classrooms, direct personal contact with diverse cultures is encouraged as a means to increase self-awareness and awareness of cultural differences. Exposure to cultural diversity appears to enhance appreciation for it. Although this may not ameliorate the lack of preparation for instructing this population, it will certainly aid in creating a welcoming classroom environment for them and allow teachers to take advantage of emerging instructional practices.

Curtin (2005b) required ELL students to enumerate the strategies they found most ineffective utilized by their teachers in their classrooms. Those most reported were being required to read in front of the peers; public correction of mistakes; isolating language-minority students from the language-majority students; overlooking language-minority students; humiliating students; providing inadequate support; rapidly covering information; providing answers without sufficient explanation or discussion; only offering one explanation; presenting too many directions; speaking too rapidly; not presenting examples; and, supplying too few practice items (Curtin, 2005b). The practices exhibited in this study have the ability to detrimentally affect both the cognitive and social development of ELLs. The lack of instruction geared toward their individual zones of proximal development, ability to inflict a self-fulfilling 
prophecy, and negatively impact their confidence in their intellectual abilities and language acquisition can affect cognitive development; while, the lack of practicing the transaction of effective interpersonal skills, and moral reasoning/behavioral issues can arise through acting out in order to receive attention, can impact the social development of the students. This lack of communication has the capability to set up any classroom for failure. While it is suitably resolved that federal, state, and district policies may mandate what teachers should be doing, teachers are in total control of the implementation process once the classroom door is closed (Curtin, 2005b; de Jong \& Harper, 2005); meaning that teachers may not be holding themselves accountable for those requirements. Subsequent interviews revealed that ELL students in mainstream classrooms preferred not to ask for more examples or explanations even if they were needed, as teachers expressed anger and frustration according to one student. This type of environment taught these students the culture of classroom survival. Each ELL student would take turns requesting assistance or more examples in order to share the brunt of teachers' unkindness or simply to avoid getting into trouble for asking for assistance from a neighbor and being accused of cheating (Curtin, 2005b).

Effective interaction strategies. Integrating the language and content of core curriculum throughout ELLs time spent in school is paramount to their success; so many teachers have adopted using exposure, interaction, use, and content as vehicles for language and literacy development (Batt, 2008; de Jong \& Harper, 2005; DelliCarpini, 2008; Gibbons, 2003; Hammond, 2008a). Maxwell (2011) reported on videos revealing interviews with middle school ELLs. These interviews were conducted in order to glean better insight into what teachers could do to enrich the communication practices in their classrooms. From her viewing, Maxwell found several ideas were presented. They are as follows: 
1. Listen to students to improve instructional skills.

2. Be more patient with comprehension.

3. Provide more time for choice reading.

4. Encourage ELL students to support one another.

5. Provide only essential information.

6. Speak at a moderate pace.

7. Talk with students individually.

8. Employ small group/partner assignments (Wertheimer \& Honigsfeld, 2000)

While these are just a few students' suggestions, they should not be taken lightly as they are most likely representative of the larger ELL population. Other suggestions of helpful communication practices include:

1. Errors in language indicate process (Ernst-Slavit et al., 2002)

2. Learn native language and English (de Jong \& Harper, 2005; Miller \& Endo, 2004; Wertheimer \& Honigsfeld, 2000 )

3. Be aware of potential emotional trauma (Miller \& Endo, 2004)

4. Watch for negative influences such as torment from peers or isolation from family (Miller \& Endo, 2004)

5. Encourage involvement in community events that promote culture (de Jong \& Harper; 2005; Miller \& Endo, 2004)

6. Welcome parents as a resource (Miller \& Endo, 2004)

7. Connections with students have important rewards such as shared pools of knowledge (Teale, 2009)

8. Place ELL students at front of classroom in order to scan students' faces for signs of comprehension, confusion, or responses to questions. (Harklau, 1994)

9. Present material through multiple methods (de Jong \& Harper, 2005; Wertheimer \& Honigsfeld, 2000)

Teale (2009) suggested that adjusting classroom instruction to meet native cultural linguistic patterns allowed students to be more engaged and participate more often. Doing so 
makes the instruction more compatible; and, while building up their culture, it also boosts students' self-esteem (Gibbons, 2003). Further, dedication to students and their learning is conveyed when lessons are presented with enthusiasm, and teachers are attentive and responsive to students' needs (Lueck, 2010). Ultimately, good teaching and sound pedagogical practices have a major impact on students' educational experiences and learning outcomes (Hammond, 2008b). When everything is taken into consideration, ELLs may fare better when their school leaders and teachers are their advocates (Black, 2005).

\section{Purpose}

From the extant literature used in this writing, the ideas and concepts conveyed regarding ELLs in mainstream classrooms are cohesive throughout almost 30 years of research; insinuating that there are effective and proven practices. These studies also include different ELL populations in terms of age and language, so that it is not limited to one specific sector of the population. However, although different populations are studied, the same suggestions for these diverse populations are offered. Interactions between teachers and children have been found to have an impact on children's development; and, given these previous findings, information regarding these interactions could prove invaluable (Han \& Bridglall, 2009). Social interaction plays an essential role in cognitive development processes according to Vygotsky's sociocultural theory; as he felt that interactions precede development (Learning Theories Knowledgebase, 2012). In one of his works, Vygotsky states that children's functions of cultural development appear first on the social level and are later followed through on an individual level (Learning Theories Knowledgebase, 2012). These notions indicate the importance of social interaction within the classroom environment, the impact that social interaction is capable of bearing upon 
cognitive and social/emotional development, and the need for more research to be dedicated to this subject. Therefore, the objectives of this study are to:

1. To describe specific kindergarten teacher and classroom characteristics (aspects of structural quality) that serve ELL and non-ELL children.

2. To examine relationships between native-English speaking kindergarten teachers and ELL and Non-ELL children within their own classroom.

2A. Specifically, do mainstream, native-English speaking, kindergarten teachers differ in their relationships with ELLs and Non-ELLs in their classrooms (assessed using the STRS)?

A. The independent variables are the comparison groups of ELL and Non-ELL students.

B. The dependent variable are the teachers' ratings on the STRS.

3. To examine if native-English speaking kindergarten teachers differ in their interactions with ELL and Non-ELL children within their own classrooms.

3A. Specifically, do mainstream, native-English speaking, kindergarten teachers differ in their interactions with ELLs and Non-ELLs in their classrooms (assessed using the Emerging Academic Snapshot)?

A. The independent variables are the comparison groups of ELL and Non-ELL students.

B. The dependent variables are the observation ratings conducted using the Emerging Academic Snapshot 


\section{CHAPTER 3: METHODOLOGY}

\section{Sample}

Following approval of the Institutional Review Board (IRB), the study was conducted within three rural counties of the eastern part of North Carolina. A minimum of 30 kindergarten teachers across three counties were asked to participate in the study as these are rural counties and have larger ELL populations (United States Census Bureau, 2013). The study was restricted to public school, full day kindergarten classrooms that enrolled at least one ELL student in their classroom.

Upon initial enrollment to any North Carolina public school, all students are required by law to complete a Home Language Survey (HLS) to determine if they are a language minority student (R. Garland, Personal Communication, May 2, 2011). Should they be deemed as such, students are then administered the WIDA Access Placement Test (W-APT) to determine the level of services to be provided for their instruction (R. Garland, Personal Communication, May 2, 2011). Only students that have been labeled by the local education agency (LEA) as language minority students were considered as ELL for the purpose of this study. Only lead teachers from the selected kindergarten classrooms participated in the study. While this sampling technique is systematic and purposeful, it is still believed to be indicative of the larger population (Bordens \& Abbot, 2008).

School demographics formed an importance basis for this study. From publicly available data (Public School Review, 2012), each public school from counties 1, 2, and 3 were searched. Each school's student population is distributed along a range of percentages in accordance with the students' races. The percentage of students of Hispanic, Asian, American Indian, and Unknown 
were added; and then multiplied by the school's total population to gain an insight into the possible ELL populations that may be present in these schools. As this number is representative of the entire K-5 population, only schools that have high percentages of students that could be ELL students were contacted to ensure that a portion of these students will represent the Kindergarten sector.

Permission was sought from 15 school administrators to conduct this study within their school. For example, see Appendix B. Nine school administrators consented, while three declined, and three did not respond. A total of 36 individual Kindergarten teachers from the nine schools were asked to participate through presentation of the study at grade level meetings. For example, see Appendix C. Teachers willing to participate were given a copy of the demographic survey, copies of the STRS measure to be completed for each student, a selfaddressed envelope with pre-paid postage for their convenience. Nineteen teachers consented

and returned data. A total of two teachers responded from County 1, nine from County 2 and eight from County 3. More details regarding these teachers will be provided in the results section.

\section{Measures}

Demographics survey. A self-constructed demographic survey was used to gather background data on teacher and classroom characteristics. Information regarding the teachers' age, gender, education level, licensure, and experience formed part of the teacher characteristics on the survey. While, information regarding the type and make-up of the classroom, services provided to the children within and outside the classroom was a part of the classroom characteristics on the survey (See Appendix D). 
Student Teacher Relationship Scale (STRS). This abbreviated scale was developed by Robert Pianta (2001) in order to measure relationships between teachers and their students. For example, see Appendix E. There are two subscales: closeness and conflict. The closeness subscale entails 8 items that measure the affection, openness and warmth a teacher experiences with a specific child. The conflict subscale measures the dissonance of the teacher-child interactions through 7 items. A total score is reflective of the overall quality of the relationship a teacher has with each individual child in their classroom. Higher total scores on each of the subscales indicate more closeness or higher conflicting relationships between the teacher and the students. Reliability is maintained at .83 within each study that the scale has been used.

Emerging Academics Snapshot. This measure is an observational tool that focuses on social academic experiences of individual children in a classroom setting that was developed by Ritchie, Howes, Kraft-Sayre, and Weiser in 2001. It is often used to describe both the children's activities and adults' responses through 27 items. For example, see Appendices F, G, and H. In a 20-second period, observers determine whether the 27 items are present or absent, and followup with a 40-second coding period. This tool can be used traditionally with one child at a time or as a "snapshot" of the entire classroom environment. While this measure does not yield scores of quality, it is an appropriate tool to use as an observation to provide specific descriptors of how children spend their time in the classroom. Reliability has been met or exceeded at .75 for this observational tool in previous studies.

\section{Establishing Inter-Rater Reliability on Emerging Academics Snapshot}

An initial observation was conducted at East Carolina University's Child Development Center to ensure proper use of the Emerging Academics Snapshot tool, as well as inter-rater reliability. The principle investigator and an undergraduate assistant conducted a total of four 
observations over a three week period. The measure was used in a Snapshot fashion and four children were observed in succession. After each observation of the fourth child, the principle investigator and undergraduate assistant convened to discuss the observation and ensure that similar interactions, activities, and engagement were surveyed during the time period. Inter-rater reliability was maintained between $85 \%$ and $89 \%$ which was acceptable to the authors.

\section{Protocol Used for Data Collection}

To complete the demographics survey and STRS on each individual student in the classroom (both ELL and Non-ELL), it was required that teachers have at least one ELL child enrolled in the classroom to ensure experience in instructing this population. STRS data was collected on a total of 408 students. Once the STRS data were analyzed, classes were selected for observation. The following criterion determined the inclusion or exclusion of those classrooms within the observations: 1) teachers' diverse training/experiences in terms of language exposure, teacher education programs, and professional development, and 2) the presence of at least 3 ELL children in the classroom.

A total of two classrooms from each school could be utilized in the study, so as not to create a nested design. A total of eight classrooms were selected for observation based on the above mentioned criterion. Teachers were contacted and asked to continue their participation in the study; however, only five of the eight responded. Finally, only five of the 19 classrooms were selected for the detailed observations due to the qualitative nature of the study and the length of observations conducted using the Emerging Snapshots; but, it still provided an accurate depiction of the interactions and relationships teachers have with their ELL and Non-ELL students. The principle investigator was the sole observer in each classroom. They found a location at the back of the classroom in order to be a passive observer and unobtrusive. 
Categories of the observation coding include: the activity setting, interaction with adults, and engagement in activities. For the purpose of this study, the EAS measure was used as a snapshot. The procedure for this was to observe four children in succession. The first child was observed for twenty seconds and their behaviors were then coded for forty seconds. This process was repeated with the second, third, and fourth students. Once each child had been observed, the observer rested and began again with the first child to ensure reliability. The observer spent a total of three hours at each observation site. 


\section{CHAPTER 4: RESULTS}

Data were analyzed using descriptive and inferential (parametric) statistics. Percentages and charts were formulated to analyze most of the demographic and observational data on teacher and classroom characteristics, while mean, standard deviation, and ANOVAs were employed to analyze data gathered from the STRS.

\section{Teacher Characteristics}

Attributes were divided into two sections; personal and professional. Personal characteristics examined variables such as teacher's age, ethnicity, education level and experience level in the field. While professional characteristics directly examined teachers specific experiences with ELL children, such as ELL training acquired as a part of professional pre or in-service teacher training and experiences teachers' have with ELL children in their past or present. The following section depicts both personal and professional characteristics of the teachers.

Personal teacher characteristics. Only lead teachers teaching kindergarten classrooms were included in this study. All participating teachers $(\mathrm{N}=19)$ were females and a large majority of these teachers were Caucasian (78.9\%), 15.8\% African American and 5.3\% were of Hispanic origin. Teachers' ages ranged between 24 to 58 years. While, their length of residency in the state of North Carolina ranged from one to 58 years with a mean of 31.98 and a standard deviation of 14.46 . Of the sample, only $5.3 \%$ of the teachers spoke a language aside from English. All teachers possessed at least a four year degree in education (68.4\%) or a related field (5.3\%); while some obtained graduate degrees $(26.3 \%)$. The majority held licensures for elementary education (63.2\%), while others were licensed in Birth through Kindergarten education (15.8\%). Others had multiple licensures (15.8\%); while one participant did not 
respond $(5.3 \%)$. Number of years in the education field ranged from one to 30 years with a mean of 10.74 and a standard deviation of 14.46. Number of years in the school at which the teachers are currently employed ranged from one to 16 years with a mean of 6.05 and a standard deviation of 5.06. Experience teaching Pre-Kindergarten ranged from zero to four years with a mean of 0.58 and a standard deviation of 1.26. Experience teaching Kindergarten ranged from one to 19 years with a mean of 5.87 and a standard deviation of 5.58. Number of months with this particular student group ranged from four to six months with a mean of 4.39 and a standard deviation of 0.59 . Table 1 depicts these results.

It was of interest to the principle investigator to further examine the characteristics specific to the teachers chosen to participate in the observation portion of this study. Of the five teachers observed, $40 \%$ had attained graduate degrees. In regards to licensure, $80 \%$ of teachers had received Elementary Licenses while $20 \%$ had attained a Birth-Kindergarten licensure. Number of years in the field ranged from three to 21.

Professional teacher characteristics. The following section depicts teachers' specific experiences with ELL children; such as, ELL training acquired as a part of professional, pre, or in-service teacher training and experiences with ELL children in teachers' past or present.

Teachers' language exposure. When surveyed regarding their perception of their exposure to different languages, teachers responded with either none (5.3\%), limited (31.6\%), or varied (63.1\%) exposure. Below, Figure 2 depicts the avenues through which teachers reported gaining such exposure. As shown, practicum experiences in teacher education programs and paid employment positions are responsible for the majority of their exposure to different languages. 
Table 1

Personal Teacher Characteristics of Sample $n=19$

\begin{tabular}{lcc}
\hline \multicolumn{1}{c}{ Characteristic } & Mean & Standard Deviation \\
\hline Length of Residency & 31.98 & 14.46 \\
Number of Years in the Field & 10.74 & 14.46 \\
Number of Years at the School & 6.05 & 5.06 \\
Experience Teaching Pre-K & 0.58 & 1.26 \\
Experience Teaching Kindergarten & 5.87 & 5.58 \\
Number of Months with Student Group & 4.39 & 0.59
\end{tabular}


Figure 2. Language Exposure Gains

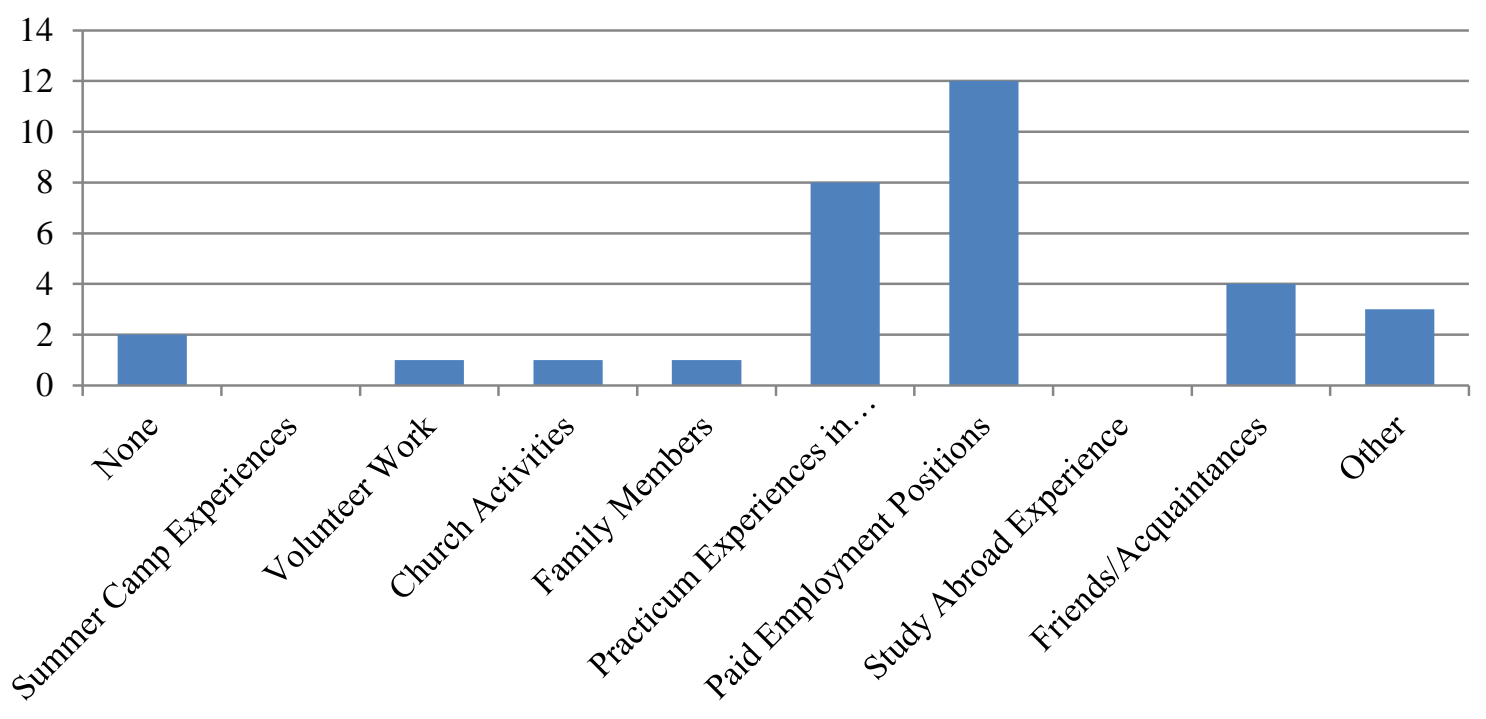


Teachers' training experiences. In their teacher education programs, $78.9 \%$ of teachers partook in practicums and field experiences. As students, 5.3\% of participants reported having received instruction regarding ELL students through a required course, while $42.1 \%$ reported having instruction merged throughout several courses. Of the teachers surveyed, $94.7 \%$ stated that they would have enrolled in courses regarding ELL students if they were available, even if it were not a required course. Regarding cultural education, $21.1 \%$ reported having a required course in their programs dedicated to the subject.

Hours of professional development experience ranged from zero to 20 hours among the participants with a mean of 4.76 and a standard deviation of 5.91; one participant (5.3\%) did not respond to this query. A large majority of the sample (89.5\%) indicated that participation in professional development was encouraged in their school. When asked if employers offered any training regarding ELL students, $47.3 \%$ of the sample confirmed that their schools did in fact offer such training. In regards to participation in such training, 31.6\% of teachers responded that they did not, while $42.1 \%$ stated that they did, and $26.3 \%$ did not respond. Conversely, all participants conveyed that they would participate in any professional development opportunities regarding ELLs if it were offered. Approximately 95\% of the participants expressed that they felt educating ELL students in their classroom was in fact their responsibility, while 5.3\% responded yes and no to this inquiry. Finally, only $36.8 \%$ of the respondents felt adequately prepared to teach ELL students in their classrooms, leaving $63.1 \%$ feeling inadequately prepared for such responsibility.

Of the five teachers observed, $80 \%$ had varied experience working with ELL students, while $20 \%$ had limited experience. The majority (80\%) had gained this experience through a paid employment position. None of the teachers observed had received instruction regarding 
ELL students during their teacher education program and only $20 \%$ had received instruction regarding culture; however, all teachers expressed an interest in enrolling despite nonrequirement. Professional development hours that the observed teachers have participated in ranged from 10-20 hours. Each of the five teachers felt as though educating ELLs was their responsibility; however, only $60 \%$ felt adequately prepared to do so.

\section{Classroom Characteristics}

Each classroom ranged from 18 to 25 students per class with a mean of 21.7 and a standard deviation of 2.22. Of the students in each class there was a range of seven to 16 boys with a mean of 11.39 and a standard deviation of 2.0; and, seven to 14 girls with a mean of 10.31 and a standard deviation of 1.89. Students with Individualized Education Plans (IEPs) ranged from zero to six with a mean of 1.70 and a standard deviation of 1.5. Number of ELL students per classroom ranged from one to 10 with a mean of 4.54 and a standard deviation of 2.35 . Table 2 represents this data.

Services provided to ELL students included programs administered in class such as English in a Flash, small group instruction, additional one on one help, verbal and visual supports, peer help and grouped work, as well as pull out instruction based in the ESL classroom. ELL students pulled out for intervention services ranged from one to nine students per classroom with a mean of 4.01 and a standard deviation of 2.63 . 
Table 2

Classroom Characteristics

\begin{tabular}{lcc}
\hline \multicolumn{1}{c}{ Characteristic } & Mean & Standard Deviation \\
\hline Students per Class & 21.7 & 2.22 \\
Boys per Class & 11.39 & 2 \\
Girls per Class & 10.31 & 1.89 \\
Students with IEPs & 1.7 & 1.5 \\
ELL Students per Class & 4.54 & 2.35 \\
ELL Students Pulled out for Intervention & 4.01 & 2.63
\end{tabular}




\section{Differences in teacher relationships with ELLs and Non-ELLs}

One of the research question of this study sought to find if any differences existed between teachers' relationships with ELL and Non-ELL students within their own classroom. This was assessed using the STRS measure $(\alpha=.70)$. Data were analyzed by reverse coding one item on the survey, then averaging the scores for the eight and seven items to generate the closeness $(\alpha=.90)$ and conflict $(\alpha=.91)$ subscales respectively. A one-way analysis of variance was conducted to evaluate the relationship between the closeness and conflict subscales for teachers' relationships with both ELL and Non-ELL students. Students were divided into two groups based upon teachers' reports of being an ELL or a Non-ELL. Table 3 depicts the following results. Teachers differed significantly in their closeness between ELL and Non-ELL children $(F(1,404)=4.6, \mathrm{p}=.033)$. Indicating, teachers shared a closer relationship with their Non-ELL children than their ELL counterparts. Interestingly, teachers also confronted higher conflicting relationship with Non-ELL children than ELL children, as indicated by the significant differences within the means across these two groups $F(1,406)=8.9, \mathrm{p}=.003$. Overall, teachers' relationships did differ for ELL and NON-ELL students within their classrooms.

\section{Differences in teacher interactions with ELLs and Non-ELLs}

The other research question of this study sought to find if any differences existed between teachers' interactions with ELL and Non-ELL students within their classroom. This was assessed using the Emerging Academics Snapshot measure. Throughout observations, items regarding activity setting, interaction with adults, and engagement in activities were coded as present or not present at the period of surveillance. Each student was observed 45 times to ensure reliability. A percentage was obtained by taking the total amount of items found present 
Table 3

Closeness and Conflict Subscale Scores

\begin{tabular}{lcccccc}
\hline \multicolumn{1}{c}{ Groups } & \multicolumn{2}{c}{ ELL } & \multicolumn{2}{c}{ Non-ELL } & & \\
\hline Subscales & $M$ & $S D$ & $M$ & $S D$ & $d f$ & $F$ \\
\hline Closeness & 4.26 & 0.739 & 4.45 & 0.718 & 1 & 4.6 \\
Conflict & 1.17 & 0.425 & 1.46 & 0.854 & 1 & 8.9
\end{tabular}


in each category, multiplying that number by 100, and dividing the product by the total number of observations, 45. This procedure was conducted for each of the four students observed. Next, observations were categorized by ELL and Non-ELL group membership. Percentages within each group were then averaged to determine if any differences existed in the teachers' interactions between the groups. The principle investigator reviewed only three point differences. Although it is not possible to discern the statistical significance of each percentage, they are able to stand on their own as a mathematical expression (S. Mai, Personal Communication, March 23, 2013).

After coding and analyzing observational data from the Emerging Academics Snapshot tool, it was determined that ELL students spent more time engaged in onlooker behaviors than their Non-ELL peers (7\% and 3\% respectively). Activity settings differed in that ELL students were more engaged in letter/sound, writing and aesthetics $(31 \%, 12 \%$, and $17 \%$ respectively) than their Non-ELL peers (24\%, $9 \%$ and $14 \%$ respectively); while Non-ELL were more engaged in pre-reading activities when compared to their ELL peers (17\% and $13 \%$ respectively). Teachers spent less time in minimal interaction with ELL students in comparison to Non-ELL students ( $0 \%$ and $3 \%$ respectively); minimal interaction constitutes responding to direct requests from the child or giving verbal directives with only a few words. Table 4 and Figure 3 describe these results.

The principle investigator was further interested in examining if teachers differed in their interactions between ELL and Non-ELL children based on their gender (males vs. females). It was found that both ELL males and females spent more time engaged in onlooker behaviors (7\% 
and $8 \%$ respectively) when compared to their Non-ELL male and female peers (2\% and $4 \%$ respectively). Teachers spent more time in elaborate interaction with ELL female students (5\%) than their Non-ELL female peers (2\%); while minimally interacting more often with Non-ELL female students than ELL female students (4\% and 1\% respectively). Additionally, teachers spent more time speaking less didactically to ELL female students ( $4 \%$ respectively) than their Non-ELL female peers (7\% respectively). Table 5 and Figure 4 denote these results. 
Table 4

Interactions between Teachers and ELL and Non-ELL Student Groups

\begin{tabular}{|c|c|c|}
\hline Observation Criteria & ELL Totals & Non-ELL Totals \\
\hline \multicolumn{3}{|l|}{ Disengaged } \\
\hline Distracted & $35 \%$ & $35 \%$ \\
\hline Onlooker & $7 \%$ & $3 \%$ \\
\hline \multicolumn{3}{|l|}{ Activity Setting } \\
\hline Routine & $4 \%$ & $4 \%$ \\
\hline Meals/Snacks & $2 \%$ & $2 \%$ \\
\hline Whole Group Time & $38 \%$ & $39 \%$ \\
\hline Free Choice/Center & $1 \%$ & $3 \%$ \\
\hline Individual Time & $26 \%$ & $26 \%$ \\
\hline Small Group Time & $28 \%$ & $26 \%$ \\
\hline \multicolumn{3}{|l|}{ Child Engagement } \\
\hline Read To & $4 \%$ & $5 \%$ \\
\hline Pre-Read/Read & $13 \%$ & $17 \%$ \\
\hline Letter/Sound & $31 \%$ & $24 \%$ \\
\hline Oral Language Development & $10 \%$ & $8 \%$ \\
\hline Chatting & $12 \%$ & $14 \%$ \\
\hline Writing & $12 \%$ & $9 \%$ \\
\hline Math & $4 \%$ & $3 \%$ \\
\hline Science & $0 \%$ & $1 \%$ \\
\hline Social Studies & $0 \%$ & $0 \%$ \\
\hline Aesthetics & $17 \%$ & $14 \%$ \\
\hline Gross Motor & $3 \%$ & $4 \%$ \\
\hline Fine Motor & $23 \%$ & $19 \%$ \\
\hline \multicolumn{3}{|l|}{ Adult Interaction } \\
\hline Routine & $0 \%$ & $1 \%$ \\
\hline Minimal & 0\% & $3 \%$ \\
\hline Simple & $9 \%$ & $10 \%$ \\
\hline Elaborated & $4 \%$ & $3 \%$ \\
\hline \multicolumn{3}{|l|}{ Adult-Child Engagement } \\
\hline Organization & $0 \%$ & $1 \%$ \\
\hline Encourages & $7 \%$ & $5 \%$ \\
\hline Scaffolds & $4 \%$ & $2 \%$ \\
\hline Didactic & $6 \%$ & $7 \%$ \\
\hline Second Language & $0 \%$ & $0 \%$ \\
\hline
\end{tabular}


Table 5

Interactions between Teachers and Male and Female ELL and Male and Female Non-ELL Student Groups

\begin{tabular}{|c|c|c|c|c|}
\hline \multirow[t]{2}{*}{ Observation Criteria } & \multicolumn{2}{|c|}{ Male } & \multicolumn{2}{|c|}{ Female } \\
\hline & ELL & Non-ELL & ELL & Non-ELL \\
\hline \multicolumn{5}{|l|}{ Disengaged } \\
\hline Distracted & $39 \%$ & $40 \%$ & $31 \%$ & $30 \%$ \\
\hline Onlooker & $7 \%$ & $2 \%$ & $8 \%$ & $4 \%$ \\
\hline \multicolumn{5}{|l|}{ Activity Setting } \\
\hline Routine & $3 \%$ & $4 \%$ & $6 \%$ & $4 \%$ \\
\hline Meals/Snacks & $2 \%$ & $0 \%$ & $1 \%$ & $3 \%$ \\
\hline Whole Group Time & $40 \%$ & $43 \%$ & $36 \%$ & $36 \%$ \\
\hline Free Choice/Center & $1 \%$ & $1 \%$ & $1 \%$ & $5 \%$ \\
\hline Individual Time & $29 \%$ & $26 \%$ & $23 \%$ & $26 \%$ \\
\hline Small Group Time & $25 \%$ & $25 \%$ & $31 \%$ & $28 \%$ \\
\hline \multicolumn{5}{|l|}{ Child Engagement } \\
\hline Read To & $4 \%$ & $4 \%$ & $4 \%$ & $5 \%$ \\
\hline Pre-Read/Read & $14 \%$ & $23 \%$ & $12 \%$ & $11 \%$ \\
\hline Letter/Sound & $28 \%$ & $26 \%$ & $34 \%$ & $21 \%$ \\
\hline Oral Language Development & $9 \%$ & $9 \%$ & $11 \%$ & $6 \%$ \\
\hline Chatting & $13 \%$ & $16 \%$ & $11 \%$ & $12 \%$ \\
\hline Writing & $10 \%$ & $9 \%$ & $14 \%$ & $9 \%$ \\
\hline Math & $5 \%$ & $3 \%$ & $3 \%$ & $4 \%$ \\
\hline Science & $0 \%$ & $1 \%$ & $0 \%$ & $0 \%$ \\
\hline Social Studies & $0 \%$ & $0 \%$ & $0 \%$ & $0 \%$ \\
\hline Aesthetics & $19 \%$ & $10 \%$ & $14 \%$ & $18 \%$ \\
\hline Gross Motor & $3 \%$ & $5 \%$ & $3 \%$ & $3 \%$ \\
\hline Fine Motor & $24 \%$ & $16 \%$ & $22 \%$ & $22 \%$ \\
\hline \multicolumn{5}{|l|}{ Adult Interaction } \\
\hline Routine & $0 \%$ & $0 \%$ & $0 \%$ & $2 \%$ \\
\hline Minimal & $0 \%$ & $2 \%$ & $1 \%$ & $4 \%$ \\
\hline Simple & $8 \%$ & $10 \%$ & $9 \%$ & $9 \%$ \\
\hline Elaborated & $4 \%$ & $4 \%$ & $5 \%$ & $2 \%$ \\
\hline \multicolumn{5}{|l|}{ Adult-Child Engagement } \\
\hline Organization & $0 \%$ & $0 \%$ & $0 \%$ & $1 \%$ \\
\hline Encourages & $6 \%$ & $5 \%$ & $8 \%$ & $6 \%$ \\
\hline Scaffolds & $4 \%$ & $2 \%$ & $4 \%$ & $3 \%$ \\
\hline Didactic & $7 \%$ & $7 \%$ & $4 \%$ & $7 \%$ \\
\hline Second Language & $0 \%$ & $0 \%$ & $0 \%$ & $0 \%$ \\
\hline
\end{tabular}


Figure 3. Interactions between Teachers and ELL and Non-ELL Student Groups

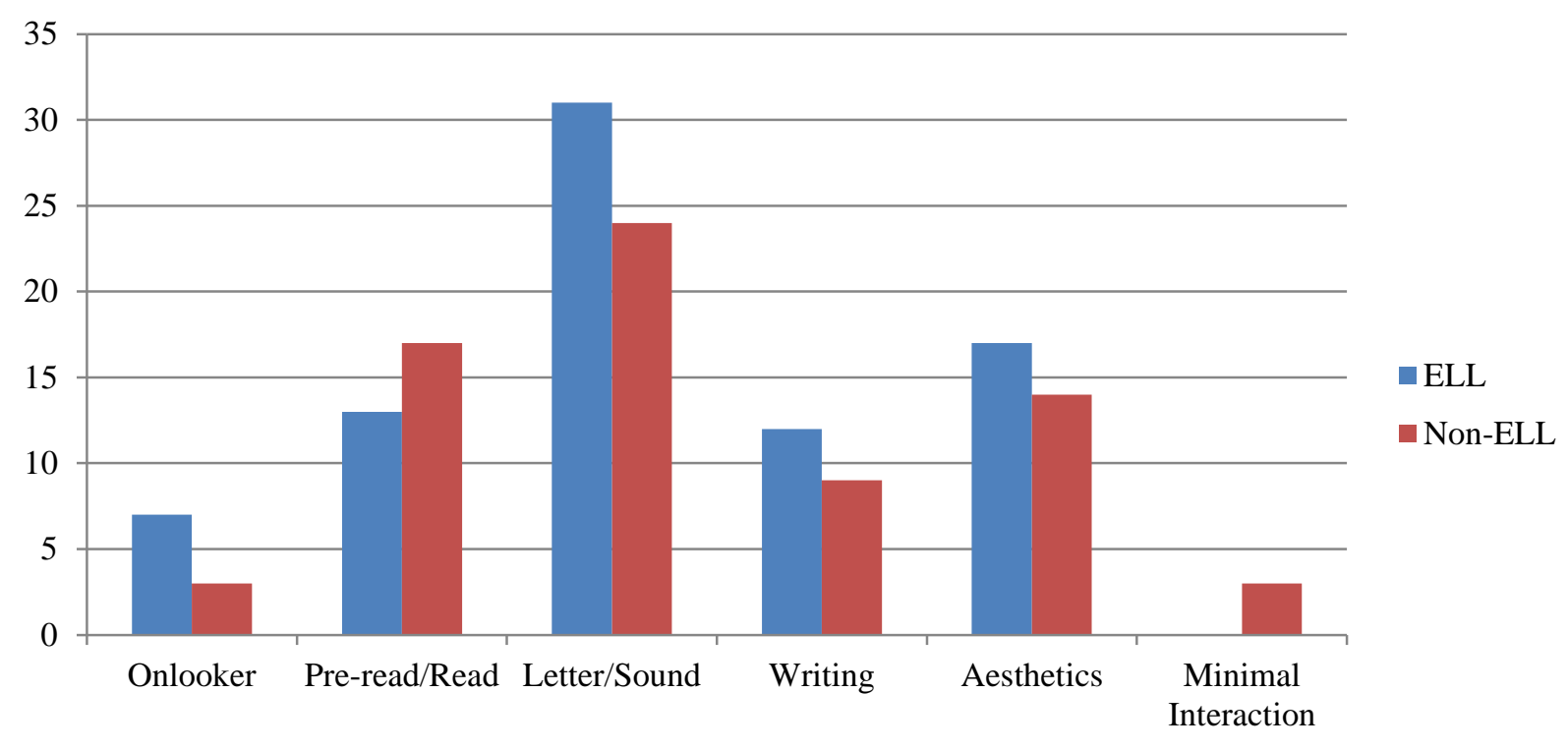

Figure 4. Gender Specific Interactions between Teachers and ELL and Non-ELL Student Groups

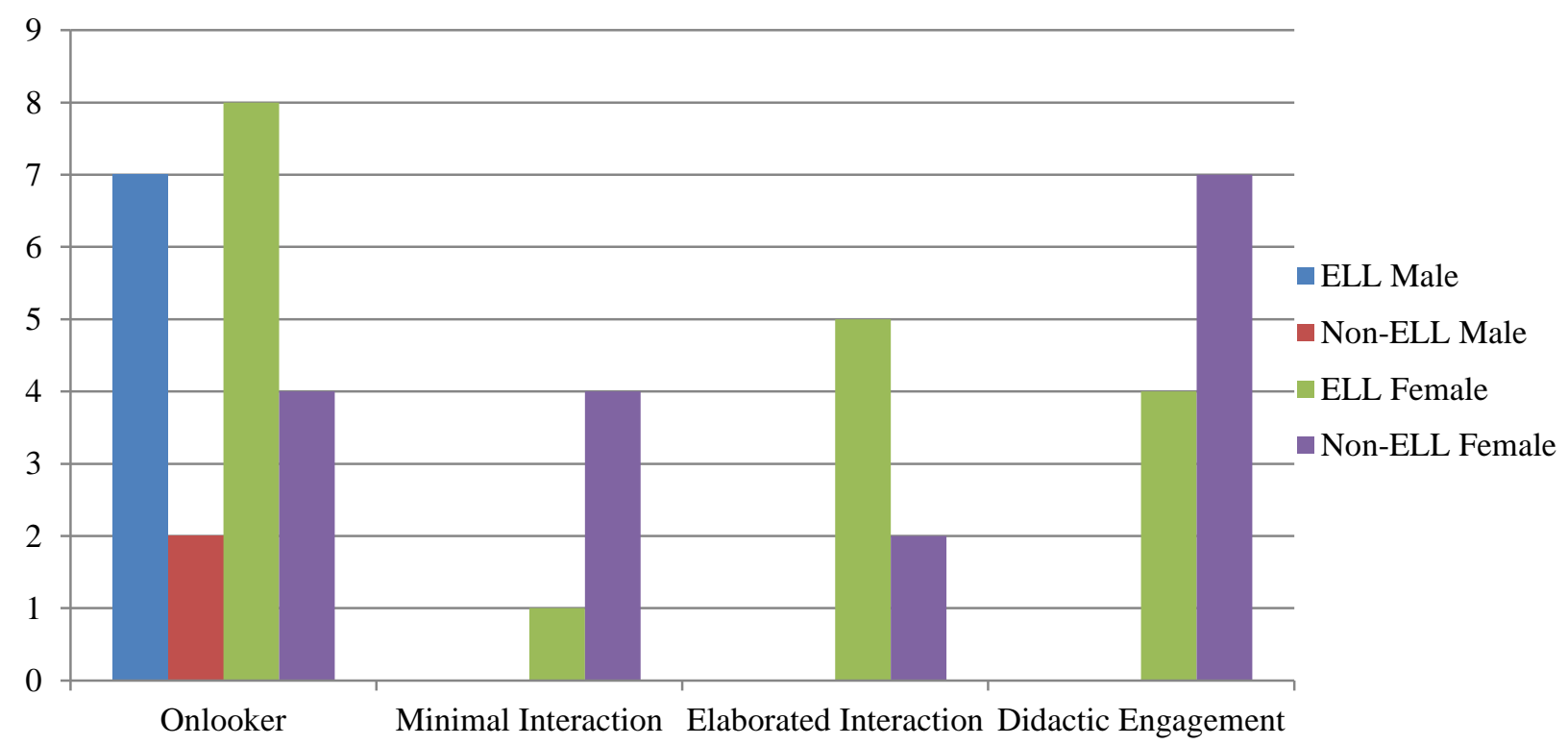




\section{CHAPTER 5: DISCUSSION}

Fundamentally this study sought to determine if kindergarten teachers differed in their relationships and interactions between ELL and Non-ELL students. As mentioned previously, information regarding the interactions between teachers and students is of great value as it has the ability to significantly impact a child's development (Han \& Bridglall, 2009). Analysis of results indicated that differences in both relationships and interactions were present. The following section will further discuss these findings, as well as implications and further directions for the study.

From the research conducted it was found that teachers maintain closer relationships with Non-ELL students than their ELL peers; however, these relationships are also more likely to be conflict laden than those with ELL students. A speculation as to why teachers may have less closeness and conflict with their ELL student group is the lack of cross cultural relationships in the classroom. The relationships are essential for a positive learning environment (Miller \& Endo, 2004, Pawan, 2008); but, are difficult to forge against substantial linguistic and conceptual differences as well as cultural barriers extant between teachers and students (Dardjowidjojo, 2001; Gibbons, 2003; Youngs \& Youngs, 2001). Another speculation for the existence of such differences in relationships could be the focus on academics due to the availability of the NC Pre-K programs in North Carolina. These programs across North Carolina are intended to offer access to high-quality educational experiences to ensure school readiness for four-year-olds that are deemed eligible. Eligibility is determined through families' low socioeconomic status, educational or developmental needs that could result in IEPs, Limited English Proficient (LEP) children, children of an active military parent, or children who have a chronic health condition (North Carolina Division of Child Development and Early Education, 2012). Student enrollment 
in an NC Pre-K program constitutes their kindergarten enrollment as the student's second year in a formal education setting. As a result, teachers may feel less inclined to focus on interaction and language development with ELL students during their kindergarten years as they have already experienced a year's worth of such instruction in Pre-K.

Depicted throughout observational data based on comparisons drawn between ELL and Non-ELL students, it was found that teachers spend much of their classroom time focused on academic material such as phonics and writing with ELL students. Contrary to previous findings that depicted teachers' beliefs of sight word mastery and phonics to be the responsibility solely of the ESL teacher (De Jong \& Harper, 2005; Penfield, 1987), teachers are beginning to share this responsibility in the mainstream classroom as well. This brings about the question is collaboration actually occurring, or are mainstream teachers required to take on this responsibility due to the presence or absence of an ESL teacher at the school? This effort could also be interpreted as building opportunities to prepare students for the requirements of high stakes achievement testing that they will be required to participate in within three years' time as mandated by NCLB (Batt, 2008; Curtin, 2005a; Curtin, 2005b; Han \& Bridglall, 2009). With such a requirement, language development and time are of the essence. According to Cummins (1989), cognitive academic language, necessary for comprehension on these high stakes achievement tests, can take up to 12 years to attain (Black, 2005; Chamot, 1983; Curtin, 2005b; de Jong \& Harper, 2005; DelliCarpini, 2008; Ernst-Slavit, Moore, \& Maloney, 2002; Wertheimer \& Honigsfeld, 2000). He further notes that achievement of CALP is a direct reflection of the academic preparation and literacy skills that students are provided in formal instruction (Ernst-Slavit et al., 2002). Teachers' focus on both phonics and writing in their classrooms can be interpreted as an effort to help students master CALP. However, when 
teachers are not directly addressing ELL students, students spend more time on-looking to their peers; indicating that they may have not understood the teachers' directions or the assignment in general, are looking at a more-knowledgeable other to help scaffold their tasks or are engaging in processes of the silent period. This crucial period of language acquisition allows ELL students to actively listen in order process the language that is being heard, apply it to the appropriate context, and replicate the language/behavior when they are prepared to do so (Ernst-Slavit et al., 2002; Krashen, 1992; Youngs \& Youngs, 2001).

Sociocultural theory states that children learn through social interactions, and in turn, actively pursue knowledge through interacting with their environments (Learning Theories Knowledgebase, 2012; Vygotsky, 1978; Vygotsky, 1986). With teachers' efforts to cultivate ELL students' CALP attainment, it is important to keep in mind that language is best learned through context. Research has indicated that language is best developed in an array of situations that promote talk and interaction. Literacy is a component of language; therefore, reading and writing develop alongside speaking and listening (Ernst-Slavit, Moore, \& Maloney, 2002). This knowledge indicates the importance of focusing on interactions and communication with ELL students within the classroom, not solely academics, which was observed in this study. It is also essential to keep in mind the importance of this interaction because teaching, itself, is fundamentally relational (Han \& Bridglall, 2009; Pawan, 2008).

It was of great interest to examine gender differences in the interactions that kindergarten teachers have with ELL and Non-ELL students because this was where interactions were found to differentiate. This information was not found when data were collapsed to form the two groups of ELL and Non-ELL students. When looking at the observational data on onlooking behaviors, it is evident that females of both ELL and Non-ELL student groups spent more time 
engaging in such behavior. While this could be interpreted in a number of ways, it is not negligent of gender stereotypical behavior. On almost all of observational criteria, teachers engaged in more frequent and variant types of interaction with female students regardless of ELL or Non-ELL group membership. This supports the claim that females receive more verbal stimulation from preschool years on to adolescence (Peterson \& Roberts, 2003).

Despite the limitations of the current study, the findings contributed to the literature by examining teacher-student relationships and interactions in a comparative manner. To date, few studies have been conducted on this topic using primary methods of data collection, using both self-report and observational tools, making this study unique and timely. While interactions themselves were not substantially different, the data posits the question of whether gender is a more important factor than the language we speak. Further, this study has lent greater insights into the experiences of teachers, ELL students and Non-ELL students in the classroom. The differences within these relationships and interactions have a number of causes and consequences that demand the attention of both individual educators and teacher education programs.

\section{Conclusions}

Although the sample size was small, the fact that more than half of the teachers surveyed felt inadequately prepared to instruct ELL students speaks volumes. Of the teachers observed, it was found that while all felt it was their responsibility to instruct ELLs in their classroom, $60 \%$ felt inadequately prepared for this task. How might this perception impact their teaching practices and classroom climate? As classroom process quality is composed of safe care, healthful care, developmentally appropriate stimulation, positive interaction with adults, encouragement of individual emotional growth, and promotion of positive relationships with 
other children (Tietze et al.,1996), teachers' feelings of inadequacy can impact each of these elements in a detrimental fashion. As most of the teachers surveyed held at least a four-year degree in education or a related field, it is essential to examine the quality of these teacher education programs in terms of preparing their constituents to accommodate for the specific needs of special populations within their classrooms.

Little less than half of the teachers surveyed had instruction regarding the ELL population merged throughout several courses in their teacher education programs, and less than one-fourth were required to enroll in a cultural education course. Should teacher education programs in North Carolina and across the nation reevaluate their requirements and incorporate more education regarding this population, it would be met with great enthusiasm. Approximately $94.7 \%$ of the teachers indicated an interest in enrollment in more culture, diversity and language based classes, had they been made available. A percentage of such magnitude, in even a small sample, makes a valued statement. While classes concentrating on culture, diversity and language are no doubt rampant within a university setting, the fact that they are not required elements of teacher education programs leaves much to be desired in terms of preparation for instruction of the ELL population in the professional sectors. Appropriations of similar classes could be easily implemented in the fine arts and humanities requirements of general education that most accredited universities uphold. Such courses would satisfy both hours necessary for the fine arts and humanities requirements and more sufficiently prepare future educators. However, this also brings about the idea that education does not always ensure preparation. Teachers may enroll and excel in a number of these courses and never feel truly prepared to teach this population. 
Additionally, less than half of the teachers reported having professional development hours that were devoted specifically to instructing the ELL population. Increasing educational standards, high stakes achievement testing, and pressures to perform duties in timely and satisfactorily manners entail a great deal of teachers' and administrative time and attention. These elements are of mounting importance but at the cost of professional development topics that could prove useful in the actual classroom. Support within the field is a necessary, all-be-it time consuming, element of the education system. Therefore, it would be worthwhile to incorporate not only useful but practical topics for professional development hours that will benefit both teachers and students alike. While classroom and school environments are dependent upon a variety of components, providing tailored support for both students and teachers is vital to help enhance the performance of each party within the classroom (Han \& Bridglall, 2009).

\section{Recommendations}

Merits of this study include that it 1) was a mixed methods design, using both self-report and observational measures; 2) used detailed demographics in order to select schools based on possible ELL populations, and classrooms based on an array of teacher and classroom characteristics. A limitation to this study is the sample size. For both portions of data collection, sample size remained small at 19 teachers returning surveys and only five teachers being observed in their classroom environment. While the differences in relationships and interactions that teachers maintain with both ELL and Non-ELL students in their classrooms are found to be statistically significant, it would be difficult to generalize these results to the larger population due to the small sample size. More participants would yield more reliable results. This could be achieved by broadening the search criteria for initial school inclusions and reaching a wider span 
of North Carolina counties. Additionally, the surveys used were a self-reported measure of the teachers' relationships with their students. Therefore it is difficult to determine if all responses provided for each student are an accurate depiction of the student-teacher relationship. In a future study, multiple tools could be utilized to assess teacher-student relationships and interactions, including ethnographic field notes. Finally, the observational method of data collection was a one-time measure over the course of a three hour period. As a future direction, multiple observational periods could be conducted within each classroom to ensure that results are indicative of the true interactions that occur in the classroom over a period of a week, month, or year rather than just one day. It would also be of note to further explore gender differences in the classroom. 


\section{REFERENCES}

Adamson, H. D. (2005). Language minority students in American schools: An education in English. Mahwah, New Jersey: Lawrence Erlbaum Associates.

August, D., \& Garcia, E. E. (1998). Language minority education in the United States: Research, policy, and practice. Springfield, Illinois: Charles C. Thomas.

Batt, E. G. (2008). Teacher's perceptions of ELL education: Potential solutions to overcome the greatest challenges. Multicultural Education, 40, 39-43.

Black, S. (2005). Easing ESL students into learning English well. American School Board Journal, 192, 36-40.

Bordens, K., \& Abbott, B. B. (2008). Research design and methods: A process approach. New York, NY; McGraw-Hill.

Boss, P.G., Doherty, W. J., LaRossa, R., Schumm, W. R., \& Steinmetz, S. K. (1993). Sourcebook of family theories and methods: A contextual approach. New York, NY: Plenum.

Bronfenbrenner, U. (2005). Making human beings human: Bioecological perspectives on human development. Thousand Oaks, CA: Sage Publications.

Carrison, C., \& Ernst-Slavit, G. (2005). From silence to a whisper to active participation: Using literature circles with ELL students. Reading Horizons, 46, 94-113.

Chamot, A. U. (1983). Toward a functional ESL curriculum in the elementary school. TESOL Quarterly, 17, 459-471.

Clair, N. (1995). Mainstream classroom teachers and ESL students. TESOL Quarterly, 29, 189-196. 
Collins, W. A., Madsen, S. D., \& Susman-Stillman, A. (2002). Parenting during middle childhood. In M. Bornstein (Ed.), Handbook of parenting (2nd ed.). (Vol. 1: Children and parenting). (pp. 73-102). Mahwah, NJ: Lawrence Erlbaum.

Cryer, D., Tietze, W., Burchinal, M., Leal, T., \& Palacios, J. (1999). Predicting process quality from structural quality in preschool programs: A cross-country comparison. Early Childhood Research Quarterly, 14, 339-361.

Cummins, J. (1989). Empowering minority students. Sacramento, CA: California Association for Bilingual Education.

Curtin, E. A. (2005a). Instructional styles used by regular classroom teachers while teaching recently mainstreamed ESL students: Six urban middle school teachers in Texas share their experience and perceptions. Multicultural Education, 12, 36-42.

Curtin, E. A. (2005b). Teaching practices for ESL students. Multicultural Education, 12, 2227.

Dardjowidjojo, S. (2001). Cultural constraints in the implementation of learner autonomy: The case in Indonesia. Journal of Southeast Asian Education, 2(2), 309-322.

De Jong, E. J., \& Harper, C.A. (2005). Preparing mainstream teachers for English-language learners: Is being a good teacher good enough? Teacher Education Quarterly, 28, 101124.

DelliCarpini, M. (2008). Success with Ells: Working with English language learners: Looking back, moving forward. The English Journal, 98, 98-101. 
Downer, J. T., López, M. L., Grimm, K. J., Hamagami, A., Pianta, R. C., \& Howes, C.

(2012). Observations of teacher-child interactions in classrooms serving Latinos and dual language learners: Applicability of the Classroom Assessment Scoring System in diverse settings, Early Childhood Research Quarterly, 27, 21-32.

Encyclopedia. (2012). Self-fulfilling prophecy. Retrieved from Encyclopedia website: http://www.encyclopedia.com/topic/self-fulfilling_prophecy.aspx

Ernst-Slavit, G., Moore, M., \& Maloney, C. (2002). Changing lives: Teaching English and literature to ESL students. Journal of Adolescent \& Adult Literacy, 46, 116-128.

Garcia, E. (1999). Student cultural diversity: Understanding and meeting the challenge Boston, MA: Houghton Mifflin.

Gibbons, P. (2003). Mediating language learning: Teacher interactions with ESL students in a content-based classroom. TESOL Quarterly, 37, 247-273.

Gibbons, P. (2008). "It was taught good and I learned a lot": Intellectual practices and ESL learners in the middle years. Australian Journal of Language and Literacy, 31, 155173.

Hammond, J. (2008a). Challenging pedagogies: Engaging ESL students in intellectual quality. Australian Journal of Language and Literacy, 31, 101-105.

Hammond, J. (2008b). Intellectual challenge and ESL students: Implications of quality teaching initiatives. Australian Journal of Language and Literacy, 31, 128-154.

Han, W. J., \& Bridglall, B. L. (2009). Assessing school supports for ELL students using the ECLS-K. Early Childhood Research Quarterly, 24, 445-462.

Harklau, L. (1994). ESL versus mainstream classes: Contrasting L2 learning environments. TESOL Quarterly, 28, 241-272. 
Honigsfeld, A. (2009). ELL programs: Not 'one size fits all'. Kappa Delta Record, 166- 171.

Jacobson, L. (2007). Early education advocates face tougher sell. Education Week, 27, 16.

Krashen, S. (1992). Principles and practice in second language acquisition. New York, NY: Pergamon.

Learning Theories Knowledgebase (2012). Social development theory. Retrieved from http://www.learning-theories.com/vygotskys-social-learning-theory.html

Ledford, J. R., Gast, D. L., Luscre, D., \& Ayres, K. M. (2008). Observational and incidental learning by children with autism. Journal of Autism Development Discord, 38, 86-103.

Lueck, C. E. (2010). ELL parents' perceptions matter. The Delta Kappa Gamma Bulletin, 77, 9-14.

Mashburn, A. J., Pianta, R. C., Hamre, B. K., Downer, J. T., Barbarin, O. A., Bryant, D., Burnchinal, M., Early, D. M., \& Howes, C. (2008). Measures of classroom quality in prekindergarten and children's development of academic, language, and social skill Child Development, 79, 732-749.

Maxwell, L. A. (2011). Teachers urged to listen to ELL students. Education Week, 4.

Mesa-Baines, A., \& Shulman, J. H. (1994). Diversity in the classroom: A casebookfor teachers and teacher educators. Hillsdale, NJ: Lawrence Erlbaum Associates.

Miller, P. C., \& Endo, H. (2004). Understanding and meeting the needs of ESL students. The Phi Delta Kappan, 85, 786-791.

North Carolina Division of Child Development and Early Education. (2012). North Carolina pre-kindergarten (NC Pre-K) program requirements and guidance. Retrieved from: http://ncchildcare.dhhs.state.nc.us/pdf_forms/NCPreProgramRequirements_08_15_2011.pdf 
Pawan, F. (2008). Content-area teachers and scaffolded instruction for English language learners. Teaching and Teacher Education, 24, 1450-1462.

Penfield, J. (1987). The regular classroom teacher's perspective. TESOL Quarterly, 21, 2139.

Peterson, C., \& Roberts, C. (2003). Like mother, like daughter: Similarities in narrative style. Developmental Psychology, 39(3), 551-562.

Phillipsen, L. C., Burchinal, M. R., Howes, C., \& Cryer, D. (1997). The prediction of process quality from structural features of child care. Early Childhood Research Quarterly, 12, 281-303.

Pianta, R. C. (1999). Enhancing relationships between children and teachers. Washington, DC: American Psychological Association.

Pianta, R. C. (2001). Student-teacher relationship scale; Professional manual. Odessa, FL: Psychological Assessment Resources.

Platt, E., Harper, C., \& Mendoza, M. B. (2003). Dueling philosophies: Inclusion or separation for Florida's English language learners? TESOL Quarterly, 37, 105-133.

Public School Review. (2012). North Carolina Public Schools. Retrieved from: http://www.publicschoolreview.com/public_schools/stateid/NC

Ritchie, S., Howes, C., Kraft-Sayre, M., \&Weiser, B. (2001). Emerging academic snapshot. Los Angeles, CA: University of California, Department of Education.

Shabani, K., Khatib, M., \& Ebadi, S. (2010). Vygotsky's zone of proximal development: Instructional implications. English Language Teaching, 3, 237-248.

Sheraga, M. (1980). ESL with advanced high school students. TESOL Quarterly, 14, 41-52. 
Strang, W., Winglee, M., \& Stunkard, J. (1993). Characteristics of secondary school-age language minority and limited English proficient youth. Final analytic report. Washington, D.C. Office of Bilingual Education and Minority Language Affairs.

Teale, W. (2009). Students learning English and their literacy instruction in urban schools. The Reading Teacher, 62, 699-703.

Tietze, W., Cryer, D., Bairrão, J., Palacios, J., \& Wetzel, G. (1996). Comparison of observed process quality in early child care and education programs in five countries. Early Childhood Research Quarterly, 11, 447-475.

United States Census Bureau. (2013). State and county quick facts. Retrieved from: http://quickfacts.census.gov/qfd/states/37000.html

United States Department of Education. (2012). No child left behind. Retrieved from: http://www2.ed.gov/nclb/landing.jhtml

Vacca-Rizopoulos, L. A., \& Nicoletti, A. (2008). Pre-service teachers' reflections on effective strategies for teaching Latino ESL students. Journal of Latinos and Education, 8, 67-76.

Van Lier, L. (1996). Interaction in the language curriculum: Awareness, autonomy, and authenticity. London: Longman.

Vygotsky, L. (1978). Mind in society. Cambridge, MA: Harvard University Press.

Vygotsky, L. (1986). Thought and language. Cambridge, MA: Massachusetts Institute of Technology Press.

Wertheimer, C., \& Honigsfeld, A. (2000). Preparing ESL students to meet the new standards. TESOL Quarterly, 9, 23-28. 
White, J. M., \& Klein, D. M. (2008). Systems framework. Family theories (pp. 1-31). Los Angeles, CA: Sage Publications.

Youngs, C. S., \& Youngs, G. A. (2001). Predictors of mainstream teachers' attitudes toward ESL students. TESOL Quarterly, 35, 97-120. 


\section{APPENDIX A: INSTITUTIONAL REVIEW BOARD (IRB) APPROVAL}

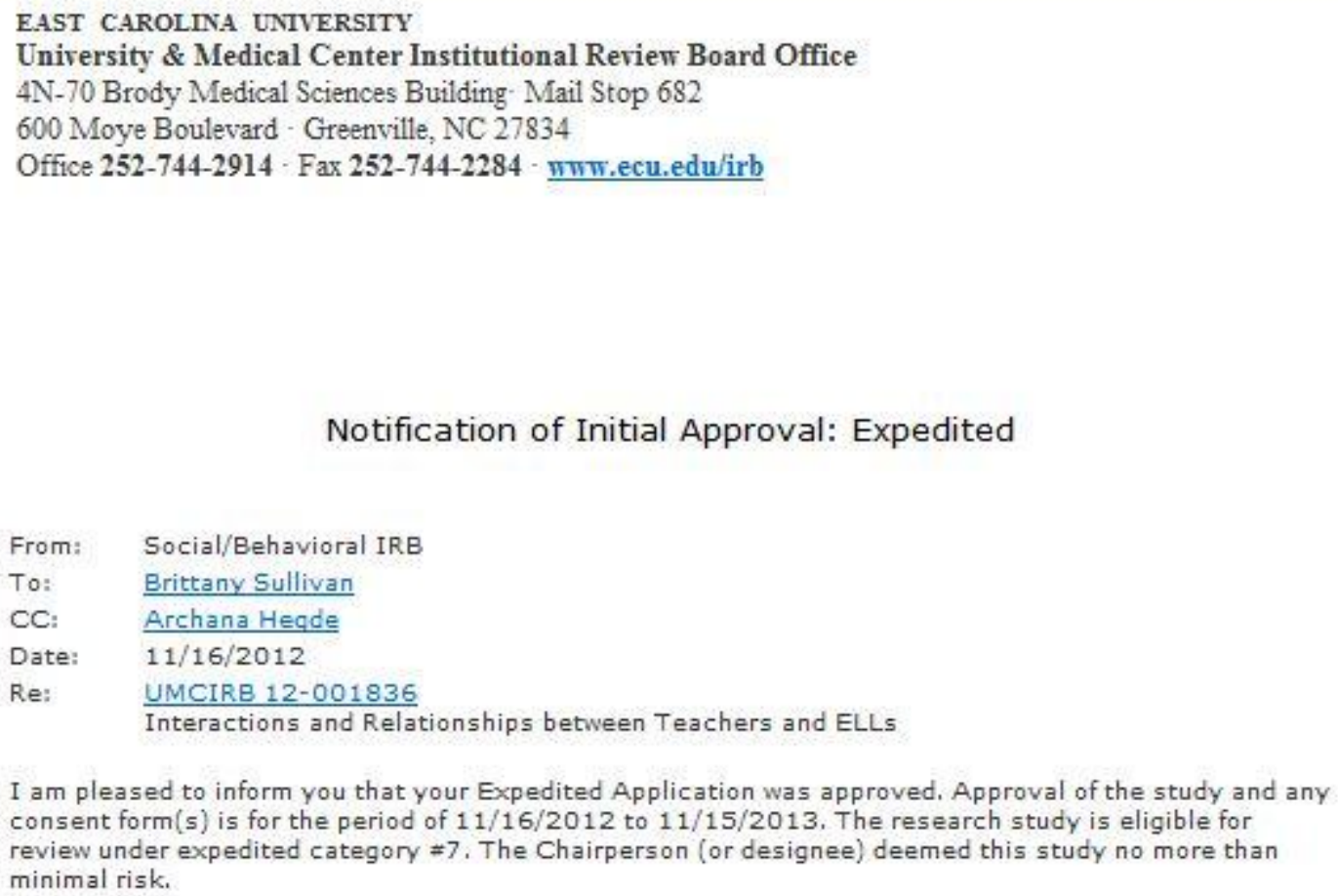

Changes to this approved research may not be initiated without UMCIRB review except when necessary to eliminate an apparent immediate hazard to the participant. All unanticipated problems involving risks to participants and others must be promptly reported to the UMCIRB. The investigator must submit a continuing review/closure application to the UMCIRB prior to the date of study expiration. The Investigator must adhere to all reporting requirements for this study.

The approval includes the following items:

Name

Demographics | History

Interactions between Kinderqarten Teachers and Enqlish Lanquaqe Learners I History

Lenior County Approval I History

STRS | History

Teachers' Informed Consent | History
Description

Surveys and Questionnaires Study Protocol or Grant Application Additional Items Surveys and Questionnaires Consent Forms

The Chairperson (or designee) does not have a potential for conflict of interest on this study. 


\section{APPENDIX B: PRINCIPALS' INFORMED CONSENT LETTER}
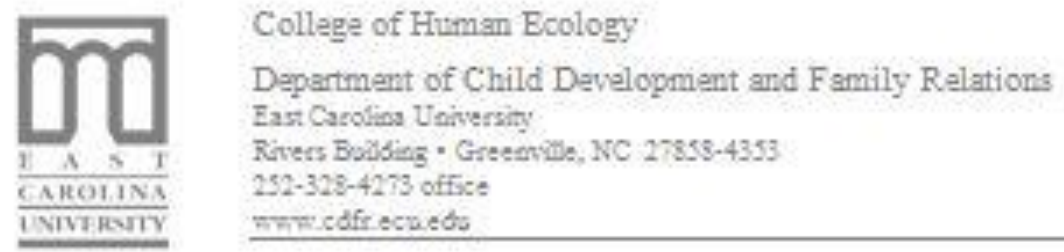

Principal's Name

School's Address

Dear

Brittany Sullivan is working on her Masters of Science in Child Development and Family Relations degree at East Carolina University. She has just completed CDFR 7000 Thesis Part $I$ a required course where students plan individual research projects to be completed and presented in another course later in their program. As part of a course assignment, Brittany Sullivan has developed research plan to be implemented over a two dsy period at This plan must be submitted and approved by a campus Institutionsl Review Board before it can be implemented; your permission for the plan is part of that review process.

Please review the research proposal and sign the bottom of this form if completing this research project titled, Interactions and Relationships between Kindergarten teachers and English Language Leamers mets with your approval.

Sincerely,

Brittany N. Sullivan

Principal Investigator

Archana Hegde, $\mathrm{PhD}$.

Profesaor and Graduate Director

Principal's Signature and Date:

I am aware, and I give consent for Brittany Sullivan to conduct a research project at

Signature

Date 


\section{APPENDIX C: TEACHERS' INFORMED CONSENT LETTER}

\section{Dear Participant,}

I am a graduate student at East Carolina University's Department of Child Development and Family Relations. I am asking you to take part in my research study entitled, "Interactions and Relationships between Kindergarten teachers and English Language Learners."

Interactions between teachers and children have been found to have an impact on children's development; therefore, information regarding these interactions could prove invaluable (Han \& Bridglall, 2009). The main purpose of this study is to examine kindergarten teachers' relationships and interactions between ELL and non-ELL students. By doing this research, I hope to learn how teachers' relationships and interactions compare between ELL and non-ELL students. Your participation in this study is completely voluntary.

You are being invited to take part in this research because of the ELL presence in your classroom. The amount of time it will take you to complete this study is approximately one to two days total.

This is a two part study. First, you will be asked to complete brief surveys; demographic (entails questions regarding teacher education and training, and classroom make-up) and the Student Teacher Relationship scale (STRS) for each student in your classroom.

You will be given these surveys during researcher's first visit. You will have a day or more to complete these surveys and completed surveys will be returned in a self-addressed envelope. All consenting teachers will complete and return these surveys. Finally, once all surveys have been returned, you may be one of 15 teachers, chosen out of a total of 30 teachers involved in this study, for a one-time observation of your interaction with your students. The sole purpose of this observation is to view and record observations occurring between teacher and the ELL students. Researcher will not interrupt or participate within any of the ongoing classroom activities.

If the researcher is awarded the grant money, then there is a built in incentives for the teachers. Each teacher completing the surveys will get a 15 dollar gift card from Wal-Mart/Target. Further, teachers considered for observations will be awarded another 15 dollar gift card for allowing and cooperating with the researcher.

Because this research is overseen by the ECU Institutional Review Board, some of its members or staff may need to review my research data. However, the information you provide will coded so it cannot be linked to you in any way. Therefore, your responses cannot be traced back to you by anyone, including me.

If you have questions about your rights as someone taking part in research, you may call the UMCIRB Office at phone number 252-744-2914 (days, 8:00 am-5:00 pm). If you would like to report a complaint or concern about this research study, you may call the Director of UMCIRB Office, at 252-744-1971.

You do not have to take part in this research, and you can stop at any time. If you decide you are willing to take part in this study, continue on with the following survey.

Thank you for taking the time to participate in my research.

Sincerely, Brittany N. Sullivan, Principal Investigator 


\section{APPENDIX D: DEMOGRAPHICS SURVEY}

Date:

\section{Please complete the following:}

\section{Personal Characteristics}

$\begin{array}{lr}\text { Gender } & \text { Race/Ethnicity } \\ \text { Age } & \text { Length of residency in North Carolina }\end{array}$

Languages in which you are fluent, aside from English

II. Education Level: (please check one)

Did not complete high school

High school diploma

NC Early Childhood Credential/CDA

Some college course work $<30$ credit hours

1 year community college diploma

2 year AA degree

2 year AAS degree

Graduate degree
4 yr. EC/CD degree

4 yr. Education degree

4 yr. degree in related field

Specify

4 yr. degree in other field

Specify

some graduate coursework

From what institution was this degree received

\section{Licensure: (please check one)}

Birth to Kindergarten

$$
\text { B-K Add-on }
$$

Pre-K Add-on

Elementary

Special Education

CDA

Other; Specify:

No licensure

\section{Experience:}

Number of years of experience in education field

Number of years at this particular school

Number of years teaching Pre-Kindergarten

Number of years teaching Kindergarten

Number of months with this particular group of Students

\section{Classroom Information}

\section{Classroom Makeup}

Number of Children in class

Number of Boys

Number of Girls 
Number of students with IEPs

Types of needs

Number of children whose primary language is not English (English Language Learner/ELL)

Primary Languages of these students

\section{Services provided to students}

Are intervention services provided to ELL students within your classroom?

$$
\text { Yes No }
$$

If yes, please specify

Are any of these services provided outside of your classroom?

Yes

No

If yes, please specify

How many of your ELL students are pulled out for intervention services (i.e., resource, primary reading teacher, volunteer programs, etc.)

I__ Students

\section{Professional Information}

\section{Language Exposure}

Experience with children/individuals whose primary language is not English: None Limited Varied

Where have you gained experience with these populations? (Check all that apply)

Summer camp experience

Volunteer Work

Church activities

Family Members

None
Practicum experiences in college Paid employment position Study Abroad experience Friends/acquaintances Other, Specify:

\section{Training}

\section{ELL Training}

In your teacher preparation program, did you receive instruction regarding English Language Learners through a required course? If yes, number of courses Course Names:

Yes No

In your teacher preparation program, was a course required focused on teaching students of culturally diverse backgrounds? If yes, number of courses Yes No

In your teacher preparation program, did you receive information relating to ELL students merged throughout a variety of courses? Yes No 
If coursework was not required, would you have enrolled in any had it been available? Yes No

In your teacher preparation program, did you participate in any practicums or field experience?

$$
\begin{gathered}
\text { Yes } \\
\text { Please elaborate }
\end{gathered}
$$

Would you participate in professional development regarding ELL students if offered?

Yes No

Does your employer offer professional development regarding ELL students?

$$
\overbrace{\text { If so, do you participate? }}^{\text {No }}
$$$$
\text { Yes }
$$$$
\text { No }
$$

Number of hours of professional development regarding ELL students completed throughout career

Is participation in Professional Development encouraged in your school? Yes _ No

Do you feel educating ELL students is your responsibility in your classroom?

$$
\text { Yes — No }
$$

Do you feel adequately prepared to teach ELL students in your classroom? Yes No 


\section{APPENDIX E: STUDENT-TEACHER RELATIONSHIPS SCALE}

Please reflect on the degree to which each of the following statements currently applies to your relationship with this student. Circle the appropriate number for each item.

\begin{tabular}{|c|c|c|c|c|c|}
\hline & 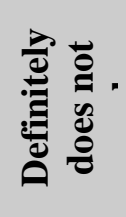 & 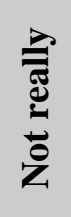 & 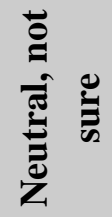 & 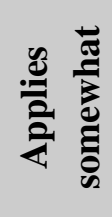 & 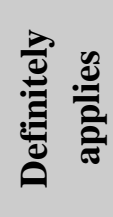 \\
\hline a. I share an affectionate, warm relationship with this child. & 1 & 2 & 3 & 4 & 5 \\
\hline $\begin{array}{l}\text { b. This child and I always seem to be struggling with each } \\
\text { other. }\end{array}$ & 1 & 2 & 3 & 4 & 5 \\
\hline c. If upset, this child will seek comfort from me. & 1 & 2 & 3 & 4 & 5 \\
\hline $\begin{array}{l}\text { d. This child is uncomfortable with physical affection or } \\
\text { touch from me. }\end{array}$ & 1 & 2 & 3 & 4 & 5 \\
\hline e. This child values his/her relationship with me. & 1 & 2 & 3 & 4 & 5 \\
\hline f. When I praise this child, he/she beams with pride. & 1 & 2 & 3 & 4 & 5 \\
\hline $\begin{array}{l}\text { g. This child spontaneously shares information about } \\
\text { himself/herself. }\end{array}$ & 1 & 2 & 3 & 4 & 5 \\
\hline h. This child easily becomes angry at me. & 1 & 2 & 3 & 4 & 5 \\
\hline i. It is easy to be in tune with what this student is feeling. & 1 & 2 & 3 & 4 & 5 \\
\hline $\begin{array}{l}\text { j. This child remains angry or is resistant after being } \\
\text { disciplined. }\end{array}$ & 1 & 2 & 3 & 4 & 5 \\
\hline k. Dealing with this child drains my energy. & 1 & 2 & 3 & 4 & 5 \\
\hline $\begin{array}{l}\text { 1. When this child arrives in a bad mood, I know we're in for } \\
\text { a long and difficult day. }\end{array}$ & 1 & 2 & 3 & 4 & 5 \\
\hline $\begin{array}{l}\text { m. This child's feelings toward me can be unpredictable or } \\
\text { can change suddenly. }\end{array}$ & 1 & 2 & 3 & 4 & 5 \\
\hline n. This child is sneaky or manipulative with me. & 1 & 2 & 3 & 4 & 5 \\
\hline $\begin{array}{l}\text { o. This child openly shares his/her feelings and experience } \\
\text { with me. }\end{array}$ & 1 & 2 & 3 & 4 & 5 \\
\hline
\end{tabular}




\section{APPENDIX F: PERMISSION TO INCLUDE EMERGING ACADEMICS SNAPSHOT CODING TEMPLATES}

From: Carollee Howes [howes@gseis.ucla.edu]

Sent: Wednesday, April 10, 2013 12:42 PM

To: Sullivan, Brittany Nicole

Subject: Re: Emerging Academics Snapshot Tool

Yes you may include them. Carollee Howes 


\section{APPENDIX G: EMERGING ACADEMICS SNAPSHOT CODEBOOK}

Below you will find a definition for each section and category on the child observation codesheet. Examples appear where applicable.

\section{Disengaged: SELECT ZERO OR ONE CODE}

If this section is coded, you may not code any other section EXCEPT for Activity Setting. If there is any kind of engagement or interaction that can be coded, it will supercede this code. If an adult speaks to the child while they are distracted, then the code is for adult interaction NOT for disengaged.

Distracted: Code if the child is:

not doing what the rest of the group is doing and is not focused on the assigned activity. The child may be aimlessly wandering or "spaced out." Code also if the child is placed in "time-out" if the child is facing a wall or is "spacing out" while in time-out.

Onlooker: Code if the child:

has a one-way awareness of a peer but there is no mutual interest in objects. This child is "looking on" to another child's activity/interaction. This category does not refer to onlooking to an adult. A child is also coded as an onlooker if she/he is placed in "time-out" by the teacher, but is looking on at his/her peers. For instance, a child may be placed in time-out and made to sit only a few feet away from his/her peers and allowed to watch from this distance.

Activity Setting: SELECT ONLY ONE CODE (EXCEPT WHEN DOUBLE-CODED WITH OUTSIDE TIME)

This set of codes captures the ACTIVITY that the teacher has prepared for the children OR for the TARGET CHILD if the activity is different from the rest of the group.

Use only small groups, not Whole Group when conducting snapshots in FCC homes.

Routine: Code when a child is engaged in:

toileting, standing in line, clean-up time, wait time between activities, waiting for materials to be passed out.

Meals-Snacks: Code when child is engaged in:

eating lunch, breakfast or snacks, or is enjoying food that the class cooked during a cooking project. 
Whole Group Time: Code when a child is engaged with:

the whole group in a teacher-initiated activity. Activities can include stories, songs, calendar instruction, discussions, book reading, demonstrations. The child's focus is on the teacher. This may include structured PE activities on the playground.

Free Choice Center: Code when a child is engaged in:

free choice activities. During this time children are able to select what and where they would like to play or learn. Activities can include individual art projects, blocks, pretend area, puzzles, reading, puppets, computers, science areas, etc. The key here is that children have chosen their activities. It does not matter if the activity they have chosen is individual or in a small group. It does not matter if the activity is with or without the teacher.

Individual Time: Code when the child has:

been assigned to work individually with or without teachers, on worksheets, independent projects, computer work etc. This is coded when this is the activity setting for the whole class or for a small group in which the target child is involved.

Small Group Time: Code when child is engaged in: small group activities that are teacher organized. Teacher organized means that the teacher decides what children are to be doing and assigns which children participate, even if the teacher is not participating in the group. These can include group art projects, writing stories, collective building, cooking projects, small group instruction, science experiments, structured PE activities, etc. May be coded when all children in the class are doing the same thing, but under the direction of teachers in smaller groupings.

A small group is coded as long as there are 2 or more children and the teacher has directed the activity or dictated what they are to be doing (see note under "Activity Settings" above)

Outside Time: Code when a child is:

OUTSIDE, regardless of what s/he is doing. This will always be double-coded with another Activity Setting.

\section{Child Engagement: SELECT ZERO, ONE, OR MORE CODES}

This section captures children's engagement in learning activities. The target child can be passively or actively engaged in all codes with the exception of gross and fine motor.

Read To: Code when a child is:

being read to by an adult. Code this category when a teacher is engaged in reading books, and stories. or engaged in talking about the author, showing the cover, or asking questions about the book/story. This does NOT include reading sentences or single words outside the context of a story. 
Pre-Read/Read: Code when a child is:

reading on her/his own or with peers, listening to a book on tape while looking at a book, involved in a sequencing activity, or recognition of whole words. Essentially this is a WHOLE LANGUAGE engagement for children. Includes flannel board stories.

Sequencing that is related to math is NOT a literacy activity and is NOT coded under pre-read.

Note: Consider the content of the books as this may be double-coded with social studies or science.

Letter/Sound Learning: Code when a child is:

practicing rhymes that help her/him recognize sounds, talking about sound-letter relationships, identifying letters, sounding out words or practicing vowel sounds,. Essentially this is about

PHONEMIC awareness.

Oral Language Development: Code when a child is:

involved in an activity or an interaction where a teacher is taking action to draw

communication from the children to build expressive language or is actively listening to children speak, by allowing them to complete their thoughts. This will always be coded with Scaffold when it is about learning vocabulary. In this case it might be Didactic (or both). The teacher may be:

- asking children questions (typically questions are open-ended and not eliciting yes/no answers

- helping children expand on their thoughts, express feelings, or resolve conflict.

- involved in verbal social interaction with the children, asking them about their lives or their activities.

- Helping children learn or practice new vocabulary. (often coded for second language learners)

Note 1: Oral Language Development is not merely giving instructions, nor is it coded when children are merely reciting or repeating words after the teacher.

Note 2: Is often, but not always coded with SCAFFOLD

Writing: Code when a child is:

writing, pretending to write, using a computer keyboard, or calculator, doing alphabet letter puzzles, writing his/her name, incorporating writing into play, such as writing grocery lists or taking orders. Also code for tracing

Note: This category encompasses writing of both numbers and letters. This will often be double-coded with Fine Motor. 
Math: Code when a child is:

rote counting, counting with 1:1 correspondence, skip counting, identifying written numerals matching numbers to pictures, making graphs, playing counting games (e.g.: dice, dominoes, Candyland, Chutes and Ladders), keeping track of how many days until a special event, counting marbles in a jar, playing Concentration or Memory with numbers. Also code when child is identifying shapes, talking about the properties of shapes (e.g. how many sides), finding shapes in the room, identifying same and different, quantitative comparing (e.g.: big/little, biggest), sorting (by color, size, shape), discerning patterns (red , blue, red, blue), measuring for cooking or size. Please code anything that has to do with the CALENDAR, even if it does not expressly refer to numbers, it is still a concept of TIME.

Science: Code when a child is:

identifying and exploring natural phenomena in their environment (bugs, leaves, weather), using science equipment (mirrors, magnets, magnifying glasses), working with sand or water (note: using funnels, pouring, sifting, packing sand for molds or castles). Includes reading books that identify or talk about animals, body parts, life-cycle of the butterfly, birth, foods and nutrition, class pets (in which case this should be double-coded with READ TO or PRE-READING). The child may be planting seeds, gathering rocks. The child may hypothesize, guess, estimate. She/he may be engaged in trial and error or experimentation, such as figuring out how to use features on a computer or how to solve a problem (such as how to open a box or fix something that is broken). Includes exploration of the senses: smell, touch, taste, sound, vision. When young children are playing with BLOCKS, they are sometimes just experimenting with horizontal and vertical building. Code for BLOCKS in SCIENCE when they are doing this instead of building actual buildings

Social Studies: Code when a child is: engaged with the intern in: talking about, reading about, or engaged in activities that inform them about their world (their neighborhood, their school, the farm, the community workers). May include block structures and it may include art work where children are drawing buildings or parts of the community. May include fantasy play, dress-up, or role-playing of family members, police officers, firefighters, doctors. May include discussions of cultural diversity, skin color, different family practices (what different families eat, what holidays they celebrate, family configurations). May include discussions or books about stereotypes, prejudice, and bias based on ethnicity, gender, age, or physical challenges. All religious studies are included in this category. Pledge of Allegiance should be coded here.

Aesthetics: Code when a child is:

engaged in art or music activities. Children may be painting, illustrating stories, sharing art work, making original drawings, using pastels or watercolors, modeling with clay or play doh,, making collages, making jewelry. Children may be listening to music (double-code with other activity if teacher purposefully has music playing during other activities), using musical instruments, dancing, or taking arts in a play. 
Gross Motor: Code when a child is:

involved in gross motor activities such as running, skipping, jumping, swinging, riding bikes, or playing games such as basketball, catch, run and chase, or bean bag throw. This also includes dancing and musical chairs, which should be double-coded with AESTHETICS. Gross Motor involves movement of the whole body. Do not code when a child is just moving briefly from place to place. This does not include physical contact that could result in injury. This can take place both inside and outside.

Fine Motor: Code when a child is:

stringing beads, building with Legos, cutting, using crayons and markers or paint brushes, pencils or pens.. This will often be double-coded with another activity. Code use of pincer grasp. (This does not include computer keyboards or use of the mouse)

Adult Interaction: SELECT ZERO OR ONE CODE Code only when there is one-on-one teacher-child interaction (can be physical or verbal) This section reflects the level of complexity of the teacher's 1:1 interaction with the target child. These categories are listed from least to most complex. Choose only the code that reflects the highest level of interaction reached in that interval, regardless of duration. The interactions may be positive or negative. The valence will not be captured here but will be picked up in the CLASS.

Routine: Code if the teacher:

interacts with target child during routine caregiving (opens a milk container, passes out materials) but does not verbally interact with the child.

Minimal: Code if the teacher:

responds to target child's direct requests for help or gives verbal directives with no reply encouraged. Teacher verbally responds with a few words ("okay," "that's right," "good," "stop that!," "sit down!", "yes she is").

Simple: Code if the teacher:

answers target child's verbal bids but does not elaborate or if the teacher asks child simple questions. Teacher responds to child with short sentences ("Yes, you need to glue that piece," "You're doing such a good job!," "I'm tired of your noise," "Where did you get that?"). Teacher may be providing simple instructions on how to begin an activity. Teacher may use gestures such as a big smile, thumbs up or a frown, glare, or eye-rolling. 
Elaborated: Code if the teacher:

engages in physical contact (high fives, hugs or holds child, yanks or grabs child, responds to a child who goes to him/her for affection or physical contact not an incidental pat or nudge), engages in reciprocal conversation that either validates a child's feelings or demonstrates teacher interest in what the child is saying. The teacher asks questions, gives the child a chance to express her/his interests or ideas, plays interactively with the child, or expands play or engagement in activities by playing with the child or by suggesting additional materials or new ideas for a game or learning activity. When children initiate a physical interaction with a teacher but there is no response from the teacher, do not code Elaborated For adult-interaction codes, you must code only what occurs within the 20 second time interval that you are observing. For example, if teacher is listening intently to a child but only says a few words in response, then you would code this as minimal or simple, not elaborated.

\section{Teacher-Child Engagement: SELECT ZERO, ONE, OR MORE CODES}

This section complements the "Adult Interaction" section and provides more detail about the specific ways in which teachers interact with students in the classroom.

- Note: Use the following codes if target child is individually engaged with the teacher OR if $s$ /he is a participant in the group with which the teacher is working.

Scaffolds: The defining characteristic is if the teacher shows an awareness of an individual child's needs and responds in a manner that supports and expands the child's learning. Code if the teacher

- is utilizing the curiosity or interest of the child

- uses child's initiations as an opportunity to add to his/her learning.

- asks open-ended questions,

- motivates through personal engagement (plays with the child-does not just demonstrate or model)

- helps child expand on his answers and thoughts

- works to link classroom activities to child's life and experiences.

- asks the child questions or poses problems that have multiple solutions, including conflict resolution.

- Is actively engaged in listening to child

Didactic: Code if the teacher is doing any of the following:

- providing instructions or giving information without interaction with the children. There is no reciprocity. The teacher talks, the children listen.

- modeling or demonstrating. The teacher is showing the children how to do something and there is just one way to do it.

- asking children questions or posing problems that have ONE CORRECT ANSWER. Teacher tries to lead the children to the correct answer. She is looking for precise words or precise numbers to answer the question or solve the problem.

- engaging children in rote activities such as counting or saying the days of the week, or practicing with flash cards.

- giving rules of conduct or lecturing about behavior or social expectations. 
Second Language: Code if the teacher is:

speaking in a language other than English or if she is moving back and forth between English and another language Sign language is coded This will be double-coded with other TeacherChild Engagement codes.

(C) Ritchie, Howes, Kraft-Sayre, \& Weiser 


\section{APPENDIX H: EMERGENT ACADEMICS SNAPSHOT CODESHEET}

Children Names/ID\#"s:

Provider/teacher names \& ID\#

Program \& ID\#
Date:

Observer

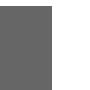

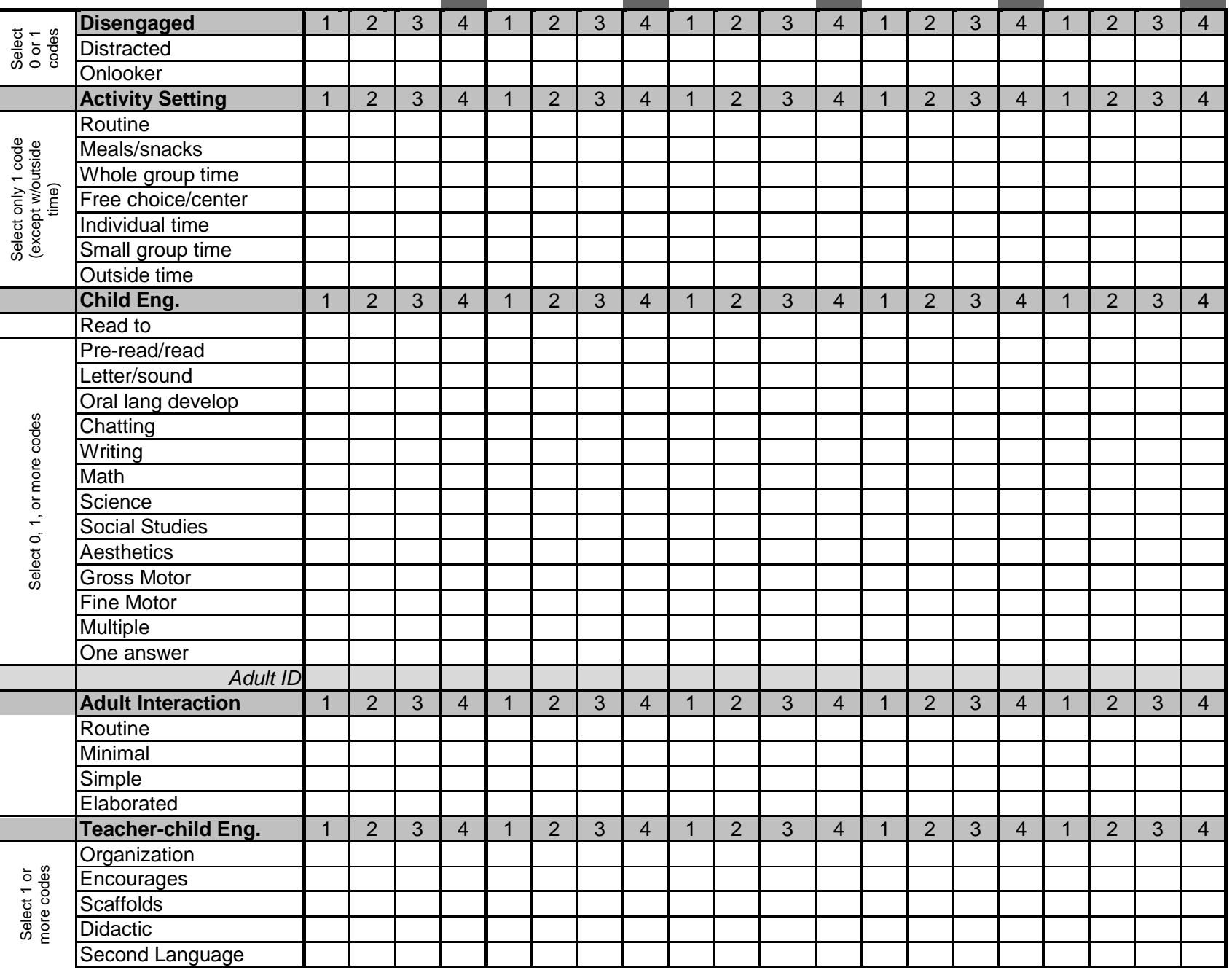

(C) Ritchie, Howes, Kraft-Sayre, \& Weiser 
